NBER WORKING PAPER SERIES

\title{
THE GAINS FROM TRADE WITH MONOPOLISTIC COMPETITION: SPECIFICATION, ESTIMATION, AND MIS-SPECIFICATION
}

\author{
Huiwen Lai \\ Daniel Trefler \\ Working Paper 9169 \\ http://www.nber.org/papers/w9169
NATIONAL BUREAU OF ECONOMIC RESEARCH
1050 Massachusetts Avenue
Cambridge, MA 02138
September 2002

We are indebted to Rob Feenstra, Gene Grossman, Jim Harrigan, Elhanan Helpman, Bo Honoré, Diego Puga, Nadia Soboleva, and Robert Stern as well as workshop participants at the NBER, Harvard University, Princeton University, the University of Tel Aviv and the University of Toronto. The views expressed herein are those of the authors and not necessarily those of the National Bureau of Economic Research.

(C) 2002 by Huiwen Lai and Daniel Trefler. All rights reserved. Short sections of text, not to exceed two paragraphs, may be quoted without explicit permission provided that full credit, including (C) notice, is given to the source. 
The Gains from Trade with Monopolistic Competition: Specification, Estimation, and Mis-Specification

Huiwen Lai and Daniel Trefler

NBER Working Paper No. 9169

September 2002

JEL No. F12, F13

\section{$\underline{\text { ABSTRACT }}$}

The difficulty of incorporating general equilibrium price effects into econometric estimating equations has deterred most researchers from econometrically estimating the welfare gains from trade liberalization. Using a paired-down CES monopolistic competition example, we show that this difficulty has been greatly exaggerated. Along the way, we estimate - indeed precisely estimate large welfare gains from trade liberalization as measured by compensating variation.

Unlike calibration methods, econometric methods allow researchers to isolate the violence done by the model to the data. We find that the CES monopolistic competition model horribly misspecifies behavioural price elasticities and general equilibrium price feedbacks. The model as conceived is therefore of limited value for analysing the effects of trade liberalization. We report a number of specification issues that should point the way to better theoretical modeling.

\section{Huiwen Lai}

SAS Institute Inc.

100 SAS Campus Drive

Cary, NC 27513-2414 USA

Huiwen.Lai@sas.com

Daniel Trefler

Department of Economics, University of Toronto, 150 St. George Street, Toronto, Ontario, M5S 3G7, Canada and NBER trefler@chass.utoronto.ca 
In the mid 1970s, as negotiations for the Tokyo Round of tariff reductions gathered momentum, a spate of papers appeared offering assessments of the potential effects of such an agreement. Weaknesses in the prevailing input-output methodology led Robert Stern to solicit new approaches from two promising junior faculty members. The first proposed a sound econometric strategy, but arrived at results that could generously be called 'mixed.' The second proposed a linearized computable general equilibrium model that yielded remarkably plausible results. The junior faculty in this apocryphal story are Ed Leamer and Alan Deardorff. (See Leamer, Stern and Baum 1977 and Deardorff, Stern and Baum 1977.) We relate this story because it marks a watershed. Deardorff's Michigan Model along with developments by John Whalley, Rick Harris and others foretold the ascendancy of computable general equilibrium modelling over econometrics in discussions of international trade policy.

The first goal of this paper is to re-establish the role of standard econometric methods for estimating the welfare gains from world-wide tariff liberalization. Our starting point is the CES monopolistic competition model with its closed-form predictions about compensating variation and bilateral trade (Dixit and Stiglitz, 1977; Helpman and Krugman, 1985). The bilateral trade prediction was initially examined by Lawrence (1987) and Saxonhouse (1989). Its popularity rose with the careful analysis of Harrigan (1993; 1996). Most of the related econometric literature has focussed on the prediction's gravity-style income terms rather than its price terms. Harrigan (1993), Haveman, Reichert and Thursby (1999), and Anderson and Mercouiller (1999) are exceptions. However, these authors all simplify the complex price term that captures both the behavioural and general equilibrium responses to falling trade costs. One cannot assess the impact of trade liberalization without knowing how economic agents respond to product prices. Thus, unless this complex price term is carefully modelled, estimating welfare gains is not possible. Fortunately, we demonstrate that estimating the mean and standard error of welfare gains is easy once price responses have been appropriately modelled. In an application to the elimination of tariffs, our estimation strategy yields large and precisely estimated gains from trade liberalization 
e.g., one-time compensating variation gains of 0.4 percent with a standard error of less than 0.1 percent.

In terms of our first goal, this paper is closely related to Eaton and Kortum (2002) who estimate complex behavioural and general equilibrium price responses in the context of a Ricardian model. They also compute the welfare gains from trade liberalization. We go a little further by treating welfare gains as an uncertain quantity whose mean and standard error must be estimated. Our aim of estimating welfare gains is shared by Feenstra (1988) and Berry, Levinsohn and Pakes (1999) who provide in-depth studies of the welfare gains from automotive sector voluntary export restraints. See Feenstra (1995) for a review of the literature.

The second goal of this paper is to econometrically assess the model for evidence of misspecification. Estimated welfare gains are model-dependent: if the model is inadequate, so too are the welfare estimates. Our focus is on whether the CES monopolistic competition model adequately captures price effects. Here we extend the work of Harrigan (1996), Jensen (2000), and Evenett and Keller (2002) who carefully examined the behavioural income elasticities implied by the model. Our work is also related to the volume-of-trade equations considered by Helpman (1987), Hummels and Levinsohn (1993, 1995), and Debaere (2002), though it is not obvious how these volume-of-trade equations can be extended to include price effects.

The analysis is built upon a new and labouriously constructed database on bilateral tariff rates for 14 importers trading with 36 exporters over the 1972-1992 period for 28 manufacturing industries. (Our sample size is dictated by the availability of scarce bilateral tariff data.) In our search for potential mis-specifications of the behavioural and general equilibrium import responses to tariff changes, we examine both within and between country-pair sample variation. Estimates based on the between country-pair sample variation exploit the fact that, for example, the United States both imports more from Canada than from Iran and has lower tariffs against Canada than Iran. That is, the 'between' estimates blithely assume that all other differences between Canada and Iran 
have been adequately modelled. This assumption is questionable. Estimates of import responses based on the within country-pair sample variation exploit the fact that U.S. imports from Canada grew after implementation of the Canada-U.S. Free Trade Agreement. That is, the 'within' estimates do not compare Canada with Iran. We find that the model's estimated behavioural and general equilibrium import responses to tariff changes explain only a modest amount of the between country-pair sample variation and none of the more informative within country-pair sample variation. This result is deeply disconcerting - it means that our welfare conclusions are being driven primarily by the model, not the data. We also report a large number of other specification and mis-specification facts that should point the way to better theoretical modelling of the effects of trade liberalization.

Returning to our first goal of estimating the welfare gains from trade liberalization, we must be very careful not to overstate what we have accomplished. The model we use is paired down as compared to the sophistication of computable general equilibrium (CGE) models. For example, while we model the effect of trade liberalization on the international distribution of production using a careful instrumental-variables approach, our specification analysis suggests that the welfare results are primarily driven by the distorting effects of tariffs on consumption decisions. In textbook terminology, we are primarily capturing the consumption distortion rather than the production distortion.

Finally, our empirical results have implications for CGE models. (The debate about econometrics versus CGE techniques is not about who can go over Niagara Falls with more style. Each has its own advantages.) A key parameter for these models is the elasticity of substitution between varieties. We demonstrate that estimates of the welfare gains from tariff reductions can be sensitive to the choice of elasticity of substitution. We estimate this parameter using the type of model and sample variation that is relevant for CGE models. Our estimates of between 5 and 8 are lower than those typically (but not always) used in the literature. For example, Brown and Stern (1989) use 15. Our estimates are more similar to those in Feenstra (1994), but often smaller than those implied by Feenstra and Levinsohn (1995). 
The outline of the paper is as follows. The first part (sections 1-6) specifies the model, estimates it, and draws out implications for the welfare gains from future rounds of tariff cuts. The second part (sections 7-11) points to various problems with the CES monopolistic competition specification, especially mis-specification of the price term.

\section{Theory}

We are interested in the standard CES monopolistic competition trade prediction. There is a single consumer in each country and preferences are internationally identical. Consumers have Cobb-Douglas preferences over goods and CES preferences over varieties. 2-stage budgeting allows us to concentrate on the decision about varieties. Let $i$ index consumer countries, let $j$ index producer countries, and let $g$ index goods. Let $\omega$ index varieties and let $N_{g j}$ be the measure (number) of varieties produced in country $j$. Let $q_{g i j}(\omega)$ be $i$ 's consumption of variety $\omega$ produced in country $j$. Let $p_{g j}(\omega)$ be the producer price and let $\tau_{g i j}$ be one plus the ad valorem tariff so that $p_{g j}(\omega) \tau_{g i j}$ is the price faced by consumers in country $i$. Given data constraints, there are no benefits from allowing $\tau_{g i j}$ to depend on $\omega$. Consumer utility is given by $U_{i}=\Pi_{g=1}^{G}\left(U_{g i}\right)^{\alpha}$ where

$$
U_{g i}=\left(\sum_{j} \int_{0}^{N_{g j}}\left(q_{g i j}(\omega) / \delta_{g i j}\right)^{\left(\sigma_{g}-1\right) / \sigma_{g}} d \omega\right)^{\sigma_{g} /\left(\sigma_{g}-1\right)} .
$$

In equilibrium, $\sigma_{g}$ is the elasticity of substitution between varieties. The $\delta_{g i j}$ are most readily thought of as Armington (1969) parameters. They have other interpretations, but we do not push on any particular one since the $\delta_{g i j}$ play almost no role in our empirical work. Given 2-stage budgeting, the country $i$ representative consumer chooses the $q_{g i j}(\omega)$ to maximize $U_{g i}$ subject to prices $p_{g j}(\omega) \tau_{g i j}$ and income $\alpha_{g} Y_{i}$ where $Y_{i}$ is national income.

Producers face constant marginal $\operatorname{costs} c_{g}$ and fixed costs $F_{g}{ }^{1}$ Utility maximization, profit maximization, and zero profits together imply (1) that the equilibrium producer

\footnotetext{
${ }^{1}$ In an earlier version of the paper we allowed $F_{g}$ and $c_{g}$ to vary internationally. This allowed us to examine international differences in costs as a source of comparative advantage. While this provided the predicted insights, the paper is already too long to include it. Lai (1999) develops this more sophisticated cost side in a multinationals context.
} 
price $p_{g j}(\omega)$ is independent of $j$ and $\omega,(2)$ that the equilibrium producer supply $q_{g j}(\omega)$ is independent of $j$ and $\omega$, and (3) that equilibrium consumer demands $q_{g i j}(\omega)$ are independent of $\omega$. Denote these by $p_{g}, q_{g}$, and $q_{g i j}$, respectively. Tedious but familiar algebra shows that optimal consumer demands $q_{g i j}$ are given by

$$
q_{g i j}=\delta_{g i j} \frac{\alpha_{g}}{p_{g}} \frac{\left(\tau_{g i j} \delta_{g i j}\right)^{-\sigma_{g}}}{\sum_{k}\left(\tau_{g i k} \delta_{g i k}\right)^{1-\sigma_{g}} N_{g k}} Y_{i} .
$$

Moving from varieties to goods, let $Q_{g j} \equiv q_{g} N_{g j}$ be country j's output of good $g$ and let $M_{g i j} \equiv q_{g i j} N_{g j}$ be country i's consumption of j's good $g$. For $i \neq j, M_{g i j}$ is $i$ 's imports from $j$. For $i=j, M_{g i i}$ is $i$ 's consumption of goods produced in $i$. Multiplying equation (2) through by $N_{g j}$ and then substituting out $N_{g j}$ using the definitions of $M_{g i j}$ and $Q_{g j}$ yields

$$
M_{g i j}=\delta_{g i j} \frac{\alpha_{g} Q_{g j}}{p_{g}} \frac{\left(\tau_{g i j} \delta_{g i j}\right)^{-\sigma_{g}}}{\sum_{k}\left(\tau_{g i k} \delta_{g i k}\right)^{1-\sigma_{g}} Q_{g k}} Y_{i} .
$$

To eliminate the unobservable $p_{g}$ and to push as hard as possible on the theory, we introduce the data identity that what country $j$ produces $\left(Q_{g j}\right)$ equals what country $j$ ships to the world, including itself $\left(\sum_{i} M_{g i j}\right)$. This is consistent with supply equalling demand. Thus, $\sum_{n} M_{g n j} \equiv Q_{g j}$ or

$$
M_{g i j} \equiv \frac{M_{g i j}}{\sum_{n} M_{g n j}} Q_{g j} .
$$

$M_{g i j} / \sum_{n} M_{g n j}$ is $i^{\prime}$ s share of $j$ 's shipments. To see that equation (4) appears repeatedly in, for example, Helpman and Krugman (1985), note that in the absence of tariffs $M_{g i j} / \sum_{n} M_{g n j}=s_{i}$ where $s_{i} \equiv Y_{i} / \sum_{n} Y_{n}$ is $i$ 's share of world income. Thus, equation (4) reduces to the familiar $M_{g i j}=s_{i} Q_{g j}$. Plugging equation (3) into equation (4) and taking logs yields

$$
\ln M_{g i j}=\ln s_{i}+\ln \Phi_{g i j}\left(\sigma_{g}, \delta_{g}\right)+\ln Q_{g j}
$$

where the price term $\Phi_{g i j}\left(\sigma_{g}, \delta_{g}\right)$ is defined as

$$
\Phi_{g i j}\left(\sigma_{g}, \delta_{g}\right) \equiv \frac{\delta_{g i j} \frac{\left(\tau_{g i j} \delta_{g i j}\right)^{-\sigma_{g}}}{\sum_{k}\left(\tau_{g i k} \delta_{g i k}\right)^{1-\sigma_{g}} Q_{g k}}}{\sum_{n} s_{n} \delta_{g n j} \frac{\left(\tau_{g n j} \delta_{g n j}\right)^{-\sigma_{g}}}{\sum_{k}\left(\tau_{g n k} \delta_{g n k}\right)^{1-\sigma_{g}} Q_{g k}}}
$$


and where $\delta_{g} \equiv\left\{\delta_{g i j}\right\}_{\forall i j}$. Setting $\delta_{g i j}=1$, the denominator of $\Phi_{g i j}$ is the 'real' income of $j^{\prime}$ s trading partners i.e., the $s_{i}$ are deflated by the CES price index. This denominator is often called the 'market potential' function for country $j$. See Hanson (1998). To summarize, imports $M_{g i j}$ depend on income $s_{i}$, a price term $\Phi_{g i j}\left(\sigma_{g}, \delta_{g}\right)$, and a data-identity term $Q_{g j}$ that enters via the identity (4).

Much of the econometric literature dealing with monopolistic competition has focussed on income effects to the exclusion of price effects e.g., gravity equations. To the extent that tariffs have been introduced they never enter into the estimating equation in the way suggested by equation (6). Rather, tariffs are introduced in a variety of ways, each a special case of the following expression: $\beta_{g} \ln \tau_{g i j}+\lambda_{g i}+\lambda_{g j}^{\prime}$ where $\lambda_{g i}$ and $\lambda_{g j}^{\prime}$ are fixed effects. This expression is equivalent to equation (6) when $\delta_{g i j}=1, \lambda_{g i}=-\ln \Sigma_{k} \tau_{g i k}^{1-\sigma_{g}} Q_{g k}, \lambda_{g j}^{\prime}=$ $-\ln \Sigma_{n}\left[s_{n} \tau_{g n j}^{-\sigma_{g}} / \Sigma_{k} \tau_{g n k}^{1-\sigma_{g}} Q_{g k}\right]$, and $\beta_{g}=-\sigma_{g}$. This has led many researchers to equate $\beta_{g}$ with $-\sigma_{g}$ and to interpret $\beta_{g}$ as a behavioural or general equilibrium response to tariffs. Yet from equations (5)-(6),

$$
\frac{d \ln M_{g i j}}{d \ln \tau_{g i j}}=\frac{d \ln \Phi_{g i j}}{d \ln \tau_{g i j}}=\beta_{g}+\frac{d \lambda_{g i}}{d \ln \tau_{g i j}}+\frac{d \lambda_{g j}^{\prime}}{d \ln \tau_{g i j}} .
$$

That is, $\beta_{g}$ has no behavioural or general equilibrium interpretation. In contrast, $\Phi_{g i j}$ captures the theoretically correct behavioural and general equilibrium import responses to tariffs. This tariff response is exactly what is at stake in discussions surrounding the effects of trade liberalization. If the $\Phi_{g i j}$ term is not fully understood empirically then neither is trade liberalization. To date, $\Phi_{g i j}$ is far from being understood empirically.

\section{The Data}

The data on trade flows come from Statistics Canada's World Trade Database. Data on income are from the World Bank. Data on gross output are from UNIDO's INDSTAT database. All these data have been cleaned up, deflated, and purchasing-power-parity (PPP) adjusted as described in Antweiler and Trefler (2002). None of the results are sensitive to the deflation method or to the use of PPP adjustments so that we need not 
go into details on these points. Industrial disaggregation is at the level of 3-digit ISIC which consists of 28 industries. The years used are 1972, 1977, 1982, 1987, and 1992.

The major data-gathering exercise for this paper has been the building of a time series on bilateral tariffs by industry and year. Most of the data come from different waves of the GATT Tariff Study which we have collected surreptitiously over the years. They also come from the UNCTAD TRAINS database. Appendix C sifts through the large number of data details. Note that what we call tariffs also includes discriminatory internal taxes. For developing countries these taxes are often substantial. The choice of countries (14 importers and 36 exporters) was dictated by the availability of these data. Table 1 reports the countries used. The 14 importers are the United States, Canada, Japan, and 11 European countries. Even though we will only be considering 14 importers, the theory states that we need the bilateral tariffs for every country in the world. See equation (6). Finding bilateral tariffs for the entire world is not feasible. Instead, we concentrated on

obtaining tariffs for the major trading partners of our 14 importers. Table 1 lists the 22 countries which, along with the initial our 14 importers, fills out the major trading partners of our 14 importers. The 1992 data for the 22 additional trading partners are from the TRAINS database. For earlier years, they are from a wide variety of sources and involve some imputation when neither member of the bilateral pair is in our list of 14 importers. See Appendix $C$ for details. The assembled bilateral, sector-specific panel data set for tariffs represents a major improvement on the types of tariff data previously used.

\section{Estimation}

Let $i=1, \ldots, 14$ index consuming countries, let $j=1, \ldots, 36$ index producing countries, let $g=1, \ldots, 28$ index 3-digit ISIC (revision 2) industries, and let $t=1972,1977,1982,1987$, 1992 index years. For each industry separately we estimate the equation

$$
\ln M_{g i j t}=\ln s_{i t}+\ln \Phi_{g i j t}\left(\sigma_{g,} \delta_{g}\right)+\ln Q_{g j t}+\lambda_{g i j}+\varepsilon_{g i j t}
$$


Table 1. List of Importers and Exporters

\begin{tabular}{|c|c|c|c|c|}
\hline \multicolumn{2}{|c|}{14 Importers and Exporters } & \multicolumn{3}{|c|}{22 Exporters } \\
\hline Europe & Other & OECD & Asia & Other \\
\hline Belgium & $\overline{\text { U.S.A. }}$ & Australia & $\overline{\text { Hong Kong }}$ & Argentina \\
\hline Germany & Canada & New Zealand & Indonesia & Brazil \\
\hline Denmark & Japan & Spain & India & Chile \\
\hline Finland & & Portugal & Korea & Ecuador \\
\hline France & & Sweden & Sri Lanka & Venezuela \\
\hline Greece & & Austria & Malaysia & \\
\hline Ireland & & Mexico & Singapore & Morocco \\
\hline Italy & & & Thailand & Tunisia \\
\hline \multicolumn{5}{|c|}{ Netherlands } \\
\hline \multicolumn{5}{|c|}{ Norway } \\
\hline United Ki & & & & \\
\hline
\end{tabular}

where the following hold. From equation (6), $\Phi_{g i j t}\left(\sigma_{g}, \delta_{g}\right)$ depends on the data $\left\{s_{i t}\right\}_{\forall i t}$, $\left\{Q_{g j t}\right\}_{\forall j t}$, and $\left\{\tau_{g i j t}\right\}_{\forall i j t} . \lambda_{\text {gij }}$ are country-pair fixed effects. We assume that the $\varepsilon_{\text {gijt }}$ are generated by an $\mathrm{AR}(1)$ process

$$
\varepsilon_{g i j t}=\rho_{g} \varepsilon_{g i j, t-1}+v_{g i j t}
$$

and that the $v_{g i j t}$ are independently distributed with zero mean and heteroscedastic variance

$$
\mathbf{E}\left(v_{g i j t}\right)^{2}=\left(\bar{s}_{i} \bar{s}_{j}\right)^{2 \omega_{g}} \eta_{g}^{2} .
$$

In equation (9), $\bar{s}_{i}$ is the average value of the five $s_{i t}$. The unknown parameters are $\sigma_{g}, \delta_{g i j}$, $\lambda_{g i j}, \rho_{g}, \omega_{g}$, and $\eta_{g}$.

We emphasize that while fixed effects are standard in the literature, $\mathrm{AR}(1)$ and generalized least squares (GLS) corrections are not. Arguably, the GLS correction is not important in a $\log$ specification though this remains to be seen. However, the $\operatorname{AR}(1)$ correction is central because without it, the sample size over-states the amount of independent sample information, thus leading to overly small standard errors and overly large $t$-statistics. (Indeed, we find that the 'effective' sample size is less than two thirds of the actual sample size where 'effective' is defined as the denominator of appendix equation A 5 below.) With 
this in mind, we find it remarkable that no other study in this area has incorporated AR(1) corrections or, for that matter, a combination of AR(1), fixed effect, and GLS corrections.

We employ a variety of estimation strategies. In the next section we consider maximum likelihood (ML) and non-linear least squares (NLS) methods. In section 5 we consider instrumental variable (IV) methods based on Arellano and Bond's (1991) approach. Details of the estimators are relegated to Appendix A and Appendix B.

\section{Empirical Results}

We start with aggregate manufacturing before moving on to results by 3-digit ISIC industry. To emphasize this we drop the $g$ subscripts. Table 2 presents estimates for aggregate manufacturing. The first column presents our baseline specification which excludes the home-bias parameter i.e., $\delta_{i j}=1$ for all $i$ and $j$. The estimate of $\sigma$ is 5.30 with a 0.40 standard error. This estimate is at the low end of the numbers usually considered in the CGE literature. For example, Harrison, Rutherford and Tarr (1997) use 8, Brown and Stern (1989) use 15, and Wei (1996) uses 20. Exceptions are Harris (1984) and Shiells and Reinert (1991) who use numbers close to unity. The estimate is also much lower than those in Harrigan (1993). His median value of $\widehat{\sigma}_{g}$ across 28 industries is 30 which is much larger than our median value (reported below) of 5.50 .

From the last line of column 1, the correlation between $\ln M_{i j t}$ and $\ln s_{i t} \Phi_{i j t} Q_{j t}$ is a high 0.88 . More precisely, this is the correlation between the scaled variables $\left(\ln M_{i j t}\right) / \psi_{i j}$ and $\left(\ln s_{i t} \Phi_{i j t} Q_{j t}\right) / \psi_{i j}$ where $\psi_{i j} \equiv\left(\bar{s}_{i} \bar{s}_{j}\right) \hat{\omega} \widehat{\eta} \sqrt{1-\widehat{\rho}^{2}}$ is the estimated standard error of $\varepsilon_{i j t}$. See equations (7)-(9). Note that all correlations and plots in this paper will use scaled variables unless stated otherwise.

The GLS correction $\widehat{\omega}=-0.12$ is negative, indicating that less weight is being given to country pairs for which both partners are small. Column 2 of table 2 drops the GLS correction by setting $\omega$ to 0 . The likelihood ratio test rejects the hypothesis of $\omega=0$ $\left(\chi_{1}^{2}=268\right)$. Despite this, setting $\omega$ to 0 barely changes $\widehat{\sigma}$. 
Table 2. Estimates for Aggregate Manufacturing

\begin{tabular}{|c|c|c|c|c|c|c|}
\hline Specification & Baseline & $\begin{array}{l}\text { No GLS } \\
(\omega=0)\end{array}$ & $\begin{array}{c}\text { No F.E. or } \\
\operatorname{AR}(1) \\
\left(\lambda_{i j}=\rho=0\right)\end{array}$ & $\begin{array}{c}\text { No Fixed } \\
\text { Effects } \\
\left(\lambda_{i j}=0\right)\end{array}$ & $\begin{array}{c}\text { No } \\
\operatorname{AR}(1) \\
(\rho=0)\end{array}$ & $\begin{array}{c}\text { No First } \\
\text { Observation }\end{array}$ \\
\hline & $(1)$ & $(2)$ & (3) & (4) & $(5)$ & (6) \\
\hline Elast. of subs. $(\sigma)$ & $\begin{array}{r}5.30 \\
(0.40)\end{array}$ & $\begin{array}{l}5.57 \\
(0.41)\end{array}$ & $\begin{array}{r}29.41 \\
(0.70)\end{array}$ & $\begin{array}{r}6.84 \\
(0.49)\end{array}$ & $\begin{array}{l}5.05 \\
(0.37)\end{array}$ & $\begin{array}{r}4.76 \\
(0.73)\end{array}$ \\
\hline $\operatorname{AR}(1)$ correction $(\rho)$ & $\begin{array}{r}0.29 \\
(0.026)\end{array}$ & $\begin{array}{r}0.18 \\
(0.026)\end{array}$ & 0.00 & $\begin{array}{r}0.96 \\
(0.0025)\end{array}$ & 0.00 & $\begin{array}{r}0.43 \\
(0.023)\end{array}$ \\
\hline GLS correction $(\omega)$ & $\begin{array}{r}-0.12 \\
(0.0071)\end{array}$ & 0.00 & $\begin{array}{r}-0.04 \\
(0.0077)\end{array}$ & $\begin{array}{r}-0.14 \\
(0.0070)\end{array}$ & $\begin{array}{r}-0.10 \\
(0.0069)\end{array}$ & $\begin{array}{r}-0.16 \\
(0.0080)\end{array}$ \\
\hline Loglikelihood & -99 & -233 & -3336 & -1129 & -155 & 288 \\
\hline Regression std. error & 0.05 & 0.44 & 2.57 & 0.05 & 0.08 & 0.02 \\
\hline Goodness of fit & 0.88 & 0.72 & 0.80 & 0.90 & 0.86 & 0.91 \\
\hline
\end{tabular}

Notes: The baseline specification is in logs with AR(1), fixed effect, and GLS corrections. See equations (7)-(9). There is no home bias $\left(\delta_{i j}=1\right.$ for all $i$ and $\left.j\right)$ in any specification. Standard errors are in parentheses. There are 2,520 observations involving 504 country pairs (14 importers x 36 exporters) and 5 years $(1972,1977,1982,1987,1992)$. (In column 6 there are only 4 years.) 'Goodness of fit' is the correlation between $\ln \left(M_{i j t}\right)$ and $\ln \left(s_{i t} \Phi_{i j t} Q_{j t}\right)$.

Column 3 shows that when the fixed effect and AR(1) corrections are omitted, $\widehat{\sigma}$ grows to 29.41. This emphatically illustrates that the between country-pair sample variation associated with previous cross-sectional studies produces radically different estimates than those based on within country-pair sample variation.

Column 4 shows that omitting the fixed effect while keeping the $\mathrm{AR}(1)$ correction raises $\widehat{\sigma}$ only a little $(\widehat{\sigma}=6.84)$. However, this is not to say that the fixed effects are unimportant. What has happened is that the fixed effects are now absorbed in the AR(1) process. This can be seen from the fact that $\widehat{\rho}$ equals 0.96 so that we are effectively differencing out the fixed effects. The likelihood ratio test statistic rejects the hypothesis of no fixed effects $\left(\chi_{1}^{2}=2,060\right)$, indicating that the fixed effects are crucial for understanding the between country-pair sample variation. This point has previously been made by Hummels and Levinsohn (1995) and others. However, since $\widehat{\rho}$ is close to unity when the $\lambda_{i j}$ are omit- 
ted, we should be thinking of dynamic interpretations of the $\lambda_{i j}$ rather than just static interpretations such as omitted distance effects. We will return to this point shortly.

The standard approach to $\mathrm{AR}(1)$ modelling involves differencing the data (e.g., $\ln M_{g i j t}-\rho \ln M_{g i j, t-1}$ and $\left.v_{g i j t}=\varepsilon_{g i j t}-\rho \varepsilon_{g i j, t-1}\right)$ and working with $\left(v_{g i j 77}, \ldots, v_{g i j 92}\right)$. Given the shortness of the five-year panel, we apply a standard correction that allows us to keep the 1972 observation. That is, it allows us to work with $\left(\varepsilon_{g i j 72}, v_{g i j 77}, \ldots, v_{g i j 92}\right)$. This correction is described fully in Appendix A. We have been careful to keep the first observation because it has frequently been pointed out that dropping it results in a serious loss of efficiency e.g., (Davidson and MacKinnon, 1993, chapter 10.6). In column 6 of table 10 we report the effect of dropping the first observation (1972). $\widehat{\sigma}$ falls only a little (to 4.76), but the standard error almost doubles (to 0.73). This highlights the importance of retaining the first, informative observation. This will prove important when we turn below to IV methods.

Figure 1 plots $\ln M_{i j t}$ against $\ln s_{i t} \Phi_{i j t}(\widehat{\sigma}) Q_{j t}$ for our baseline specification. Both are scaled by the GLS correction so that the units are standard deviations. The high correlation of 0.88 is reflected in the plot. In the plot, a 'o' marks domestic observations $(i=j)$ and an ' $x$ ' marks foreign observations $(i \neq j)$. The former all lie above the predicted $45^{\circ}$ line whereas the latter mostly lie below. This graphically illustrates that trade is missing relative to its theoretical prediction, just as in Trefler's (1995) "case of the missing trade."

Figure 1 suggests that the results may be sensitive to the inclusion of domestic observations. Table 3 investigates. Column 1 is the baseline specification from table 3 . Column 2 shows that $\widehat{\sigma}$ does not change when the domestic consumption observations are excluded.

Column 3 of table 3 introduces home bias. In the baseline specification we imposed $\delta_{i j}=1$ for all $i$ and $j$. In the home bias specification we restrict the $\delta_{i j}$ so that $\delta_{i i}=1$ for all $i$ and $\delta_{i j}=\delta$ for $j \neq i . \delta$ is estimated to be 0.86 , indicating that 1 unit of a foreign good provides the same utility as 0.86 units of a domestic good. That is, there is home bias. 


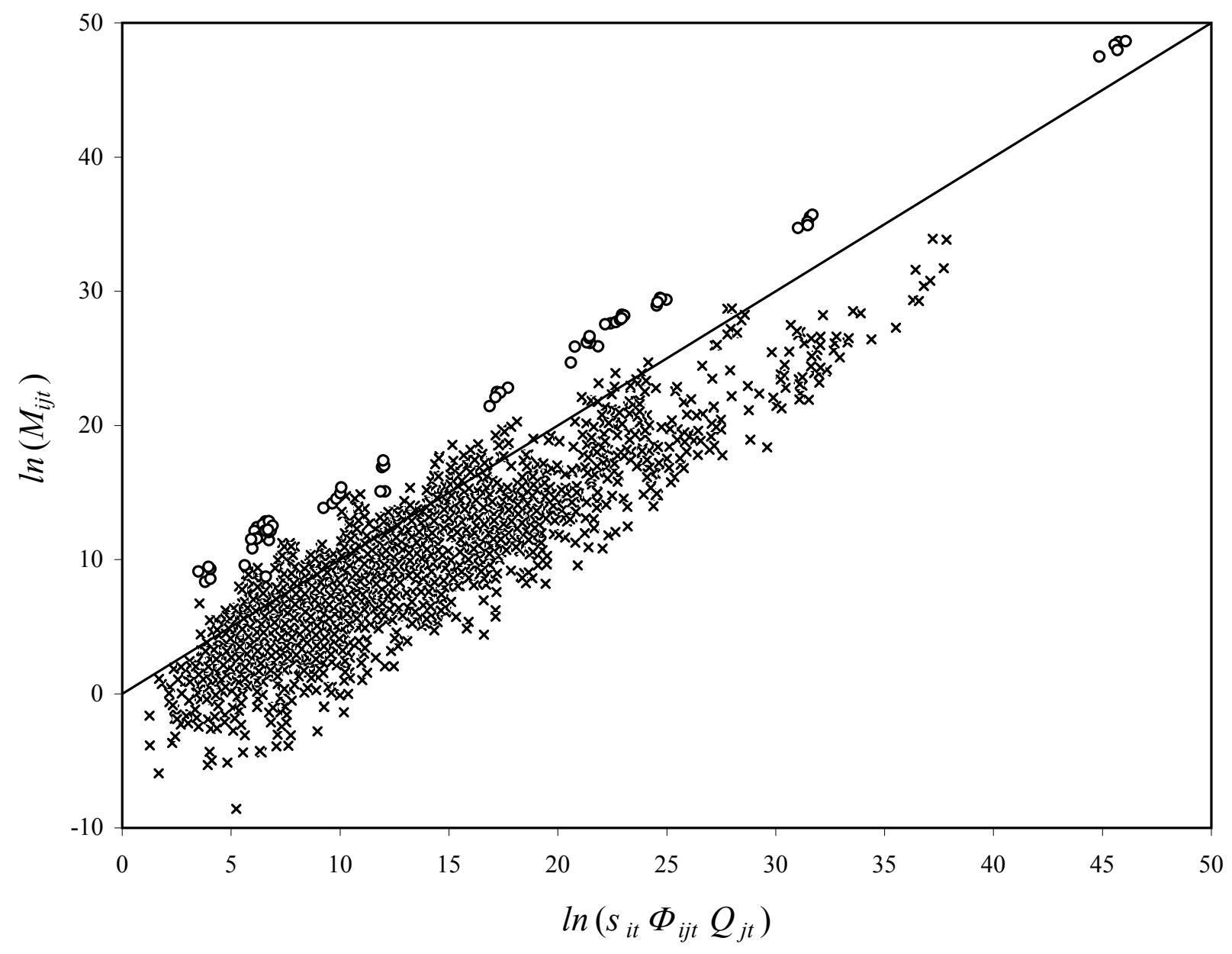

Figure 1. Model Fit: $\ln M_{i j t}$ vs. $\ln s_{i t} \Phi_{i j t} Q_{j t}$

However, the $t$-statistic for the hypothesis that $\delta=1$ is $1.08 .^{2}$ Further, our estimates of $\delta$ are very fragile, meaning that they bounce around substantially across specifications. In particular, while they are rarely in excess of 1.2 , they often fall to 0.001 which is so low as to be economically meaningless. Such low values of $\widehat{\delta}$ are reminiscent of Trefler's (1995) results on home bias. It is important to note that no matter what value $\widehat{\delta}$ takes, the estimate of $\sigma$ is always close to its baseline value of 5.30. We thus restrict $\delta$ to equal unity in all that follows.

Column 4 of table 3 examines potential outliers. There are two exporters in our data base with unusual data, India with its tariffs and other discriminatory internal taxes in

\footnotetext{
${ }^{2}$ If $\delta_{i i}$ is set equal to $\delta$ rather than 1 , then $\delta$ is not be identified. See equation (6). This means that very few observations - only those with $(i, i)$ subscripts - contribute sample variation useful for estimating $\delta$. Thus, we expect imprecise estimates of $\delta$.
} 
Table 3. Alternative Specifications for Aggregate Manufacturing

\begin{tabular}{|c|c|c|c|c|c|}
\hline \multirow[t]{2}{*}{ Specification } & Baseline & $\begin{array}{c}\text { No Domestic } \\
\text { Observations } \\
(i=j \text { Omitted })\end{array}$ & $\begin{array}{c}\text { Home } \\
\operatorname{Bias}\left(\delta_{i j}\right) \\
\end{array}$ & $\begin{array}{l}\text { Omit Hong } \\
\text { Kong and } \\
\text { India }\end{array}$ & $\begin{array}{c}\text { Nonlinear } \\
\text { Least } \\
\text { Squares }\end{array}$ \\
\hline & $(1)$ & $(2)$ & (3) & $(4)$ & $(5)$ \\
\hline \multirow[t]{2}{*}{ Elasticity of substitution $(\sigma)$} & 5.30 & 5.27 & 5.47 & 5.13 & 5.44 \\
\hline & $(0.40)$ & $(0.40)$ & $(0.47)$ & $(0.47)$ & $(0.44)$ \\
\hline \multirow[t]{2}{*}{ Home Bias $(\delta)$} & & & 0.86 & & \\
\hline & & & $(0.13)$ & & \\
\hline \multirow[t]{2}{*}{$\operatorname{AR}(1)$ Correction $(\rho)$} & 0.29 & 0.28 & 0.28 & 0.30 & 0.45 \\
\hline & $(0.026)$ & $(0.027)$ & $(0.027)$ & $(0.026)$ & $(0.30)$ \\
\hline \multirow[t]{2}{*}{ GLS correction $(\omega)$} & -0.12 & -0.12 & -0.12 & -0.12 & -0.12 \\
\hline & $(0.0071)$ & $(0.0073)$ & $(0.0078)$ & $(0.0071)$ & $(0.0074)$ \\
\hline Loglikelihood & -99 & -127 & -99 & -42.35 & -129 \\
\hline Regression standard error & 0.05 & 0.06 & 0.06 & 0.05 & 0.05 \\
\hline $\operatorname{Corr}\left(\ln \left(M_{i j t}\right), \ln \left(s_{i t} \Phi_{i j t} Q_{j t}\right)\right)$ & 0.88 & 0.89 & 0.87 & 0.90 & 0.88 \\
\hline
\end{tabular}

Notes: The baseline specification is in logs with AR(1), fixed effect, and GLS corrections and there is no home bias ( $\delta$ $=1$ for all $i$ and $j$ ). Standard errors are in parentheses. There are 2,520 observations in the baseline specification.

excess of 100 percent and Hong Kong with its Chinese entrepôt trade and low tariffs. Column 4 shows that India and Hong Kong are not influential observations.

Column 5 of table 3 shows that it does not matter whether we move from our baseline maximum likelihood (ML) estimator to a nonlinear least squares (NLS) estimator ( $\widehat{\sigma}=$ 5.44). Details of the two estimators appear in Appendix A.

To summarize, we have considered an array of specifications dealing with fixed effects, serial correlation, heteroscedasticity, treatment of first observations, ML versus NLS, potential outliers (domestic observations, Hong Kong, and India) and the role of home bias. All of these point to an estimate of $\sigma$ tightly centered around 5 . This is lower than estimates used by most modelers of the effects of trade liberalization e.g., Brown and Stern (1989) use 15 . 


\section{IV Results}

So far, we have treated $\ln s_{i t} \Phi_{i j t}(\sigma) Q_{j t}$ as being exogenous. The issue of endogeneity is clearly important. The first thing to observe is that the model can equivalently be written as $\ln M_{i j t}-\ln s_{i t}-\ln Q_{j t}=\ln \Phi_{i j t}(\sigma)+\lambda_{i j}+\varepsilon_{i j t}$ which highlights the fact that what is important is $\mathbf{E}\left[\ln \Phi_{i j t}(\sigma) \mid \varepsilon_{i j t}\right]=0$ rather than $\mathbf{E}\left[\ln s_{i t} \mid \varepsilon_{i j t}\right]=0$ or $\mathbf{E}\left[\ln Q_{j t} \mid \varepsilon_{i j t}\right]=0$. At various points of this paper we will want to modestly model the process governing the endogenous evolution of the location of production. That is, we will sometimes want $\ln Q_{j t}$ as a right-hand-side variable and sometimes as a left-hand-side variable. Adopting notation that is flexible enough to accommodate this, we re-write equation (7) as

$$
y_{i j t}=x_{i j t}(\sigma)+\lambda_{i j}+\varepsilon_{i j t}
$$

where

$$
y_{i j t}-x_{i j t}(\sigma)=\ln M_{i j t}-\ln s_{i t}-\ln Q_{j t}-\ln \Phi_{i j t}(\sigma) .
$$

and where $x_{i j t}(\sigma)$ includes $\ln \Phi_{i j t}(\sigma)$. Obviously we have not yet defined $y_{i j t}$ and $x_{i j t}(\sigma)$ individually. This will come shortly.

The ML estimator of the previous section maximized the likelihood of $\left(\varepsilon_{i j 72}, v_{i j 77}, \ldots\right.$, $\left.v_{i j 92}\right)$ where $v_{i j t} \equiv \varepsilon_{i j t}-\rho \varepsilon_{i j, t-1}$. To further examine the $v_{i j t}$, consider

$$
y_{i j t}=\rho y_{i j, t-1}+\Delta_{\rho} x_{i j t}(\sigma)+(1-\rho) \lambda_{i j}+v_{i j t} \quad t \geq 2
$$

where $\Delta_{\rho}$ is the generalized difference operator given by

$$
\Delta_{\rho} x_{i j t}(\sigma) \equiv x_{i j t}(\sigma)-\rho x_{i j, t-1}(\sigma) \quad t \geq 2
$$

and where the time index is now $t=1,2, \ldots, T$ instead of $t=1972,1977, \ldots, 1992$. Equation (12) highlights the fact that we are dealing with a dynamic panel. It also brings to the fore two issues of endogeneity. First, as observed by Nickell (1981), estimation methods that difference out the $\lambda_{i j}$ (as did the non-linear fixed effects estimator we used in the previous section) induce a correlation between the $y_{i j, t-1}$ and the transformed 
residuals. The easiest way to see this is to difference equation (12):

$$
y_{i j t}-y_{i j, t-1}=\rho\left(y_{i j, t-1}-y_{i j, t-2}\right)+\left(\Delta_{\rho} x_{i j t}(\sigma)-\Delta_{\rho} x_{i j, t-1}(\sigma)\right)+\left(v_{i j t}-v_{i j, t-1}\right) \quad t \geq 3 .
$$

Since $\mathbf{E}\left(y_{i j, t-1}-y_{i j, t-2}\right)\left(v_{i j t}-v_{i j, t-1}\right)=-\mathbf{E} y_{i j, t-1} v_{i j, t-1} \neq 0$, consistent estimation requires IV methods. A second problem arises when the $x_{i j t}(\sigma)$ in equation (10) are endogenous i.e., $\mathbf{E} x_{i j t} \varepsilon_{i j t} \neq 0$. This implies that $\mathbf{E} \Delta_{\rho} x_{i j t} v_{i j t} \neq 0$ in equation (13). Both sources of endogeneity can be handled using a modification of Arellano and Bond's (1991) generalized method of moments (GMM) approach. They propose to estimate equation (13) using instruments that exploit the full set of moment restrictions. ${ }^{3}$ These moment restrictions are

$$
\mathrm{E} y_{i j s}\left(v_{i j t}-v_{i j, t-1}\right)=0 \quad s=1, \ldots, t-2 \text { and } t \geq 3
$$

and, setting the unobserved initial $x_{i j 0}(\sigma)$ to 0 for notational convenience,

$$
\mathbf{E} \Delta_{\rho} x_{i j s}\left(v_{i j t}-v_{i j, t-1}\right)=0 \quad s=1, \ldots, t-2 \text { and } t \geq 3 \text {. }
$$

We will also find it useful to report results based on the assumption that the $x_{i j t}$ are exogenous. Then we can exploit the additional moment restrictions

$$
\mathbf{E} \Delta_{\rho} x_{i j s}\left(v_{i j t}-v_{i j, t-1}\right)=0 \quad s=t-1, t \text { and } t \geq 3 \text {. }
$$

We will estimate equation (13) using the Arellano and Bond estimator and the moment restrictions (14)-(16). There are a large number of details that we relegate to Appendix B.

Column 1 of table 4 repeats the ML estimates from column 2 of table 2 in which $\left(y_{i j, t-1}-y_{i j, t-2}\right)$ and $\left(x_{i j t}-x_{i j, t-1}\right)$ are treated as exogenous. To keep matters simple, we forego the GLS correction by setting the $\omega_{g}$ of equation (9) to 0 . The remaining columns report various IV estimates. In the top panel, $\Delta_{\rho} x_{i j t}(\sigma)$ is treated as exogenous while in the bottom panel it is treated as endogenous. Each of columns 2-5 reports results using different definitions of $y_{i j t}$ and $x_{i j t}$. These definitions appear in the bottom two rows of the table. For example, in column 2, $y_{i j t}$ is defined as $\ln M_{i j t}$ and $x_{i j t}$ is defined as $\ln s_{i t} \Phi_{i j t} Q_{j t}$.

\footnotetext{
${ }^{3}$ Note that while equation (13) is not quite the same as the Arellano and Bond set-up $\left(\Delta_{\rho} x_{i j t}\right.$ is both endogenous and non-linear in $\sigma$ ), it is straightforward to extend their results to this setting.
} 
Table 4. IV Results With $\Delta y_{i j t}$ and $\Delta_{\rho} x_{i j t}$ Endogenous

\begin{tabular}{|c|c|c|c|c|c|}
\hline \multirow[t]{2}{*}{ Specification } & \multirow{2}{*}{$\frac{\mathrm{ML}}{(1)}$} & \multicolumn{4}{|c|}{ GMM Instrumental Variables } \\
\hline & & $(2)$ & (3) & (4) & $(5)$ \\
\hline \multicolumn{6}{|l|}{$\Delta_{\rho} x_{i j t}$ Exogenous } \\
\hline Elas. of substitution $(\sigma)$ & $\begin{array}{r}5.57 \\
(0.41)\end{array}$ & $\begin{array}{r}5.03 \\
(12.34)\end{array}$ & $\begin{array}{r}7.05 \\
(1.70)\end{array}$ & $\begin{array}{r}5.50 \\
(2.31)\end{array}$ & $\begin{array}{r}7.08 \\
(1.88)\end{array}$ \\
\hline $\operatorname{AR}(1)$ correction $(\rho)$ & $\begin{array}{r}0.18 \\
(0.026)\end{array}$ & $\begin{array}{r}0.56 \\
(0.25)\end{array}$ & $\begin{array}{r}\mathbf{0 . 6 3} \\
(0.27)\end{array}$ & $\begin{array}{r}0.58 \\
(0.30)\end{array}$ & $\begin{array}{r}\mathbf{0 . 6 1} \\
(0.175)\end{array}$ \\
\hline Hausman test statistic & & $\begin{array}{r}2.56 \\
(0.722)\end{array}$ & $\begin{array}{r}9.78 \\
(0.992)\end{array}$ & $\begin{array}{r}1.90 \\
(0.613)\end{array}$ & $\begin{array}{r}9.05 \\
(0.989)\end{array}$ \\
\hline \multicolumn{6}{|l|}{$\Delta_{\rho} x_{i j t}$ Endogenous } \\
\hline Elas. of substitution $(\sigma)$ & & $\begin{array}{r}3.31 \\
(29.83)\end{array}$ & $\begin{array}{r}3.66 \\
(1.95)\end{array}$ & $\begin{array}{r}3.22 \\
(2.21)\end{array}$ & $\begin{array}{r}8.35 \\
(4.63)\end{array}$ \\
\hline $\operatorname{AR}(1)$ correction $(\rho)$ & & $\begin{array}{r}0.59 \\
(0.18)\end{array}$ & $\begin{array}{r}0.64 \\
(0.28)\end{array}$ & $\begin{array}{r}0.62 \\
(0.19)\end{array}$ & $\begin{array}{r}\mathbf{0 . 5 9} \\
(0.29)\end{array}$ \\
\hline Hausman test statistic & & $\begin{array}{r}5.70 \\
(0.942)\end{array}$ & $\begin{array}{r}2.72 \\
(0.744)\end{array}$ & $\begin{array}{r}5.19 \\
(0.925)\end{array}$ & $\begin{array}{r}12.93 \\
(0.998)\end{array}$ \\
\hline \multicolumn{6}{|l|}{ Instrument Set } \\
\hline$y_{i j t}=$ & & $\ln M_{i j t}$ & $\ln M_{i j t} / s_{i t} Q_{j t}$ & $\ln M_{i j t} / Q_{j t}$ & $\ln M_{i j t} / s_{i t}$ \\
\hline$x_{i j t}=$ & & $\ln s_{i t} \Phi_{i j t} Q_{j t}$ & $\ln \Phi_{i j t}$ & $\ln s_{i t} \Phi_{i j t}$ & $\ln \Phi_{i j t} Q_{j t}$ \\
\hline
\end{tabular}

Notes: 1) The ML estimator treats both $\Delta y_{i j t}$ and $\Delta_{\rho} x_{i j t}$ as exogenous. 2) In the top panel, the IV estimator treats $\Delta y_{i j t}$ as endogenous and $\Delta_{\rho} x_{i j t}$ as exogenous. In the bottom panel, the IV estimator treats both $\Delta y_{i j t}$ and $\Delta_{\rho} x_{i j t}$ as endogenous. 3) In the $\sigma$ and $\rho$ rows, standard errors are in parentheses. See footnote 4 for a discussion of standard errors. 4) In the 'Hausman test statistic' rows, $p$-values are in parentheses. Large $p$-values indicate rejection of exogeneity. Boldface indicates that exogeneity is rejected at about the one percent level. 
The importance of the definitions is that they determine the choice of instruments via the moment restrictions (14)-(16). For example, in column 2, the instrument set is built up from lagged values of $\ln M_{i j t}$ and $\ln s_{i t} \Phi_{i j t} Q_{j t}$ whereas in column 3 the instrument set is built up from lagged values of $\ln M_{i j t} / s_{i t} Q_{j t}$ and $\ln \Phi_{i j t}$. See Appendix B for details.

The most obvious feature of the table, and the one that appears in every specification, is that the $\widehat{\rho}_{\mathrm{IV}}$ are about three times larger than $\widehat{\rho}_{\mathrm{ML}}$. This is exactly what one would expect from attenuation bias due to endogeneity. The value of $\widehat{\rho}_{\text {IV }}$ is strikingly large: a typical value of 0.6 implies, for instance, that a one percent rise in today's imports transmits a 0.36 percent change in imports a decade later. Notice that this is true even though we have controlled for fixed effects. It highlights the fact that fixed effects fail to capture systematic components of bilateral import dynamics. The Hausman (1978) test for endogeneity indicates that endogeneity is rejected at about the one percent level in column 3 (top panel) and column 5 (both panels). These are indicated in boldface.

Next consider the $\widehat{\sigma}$ of table 4 . In the three specifications for which exogeneity is rejected (the boldface specifications), $\widehat{\sigma}$ takes on the values of 7.05, 7.08, and 8.35. These are somewhat higher than their ML counterpart of 5.57. There is an intriguing explanation of this that runs in terms of the hypothesis that imports are a market-disciplining device. (See Levinsohn, 1993; Harrison, 1994.) Consider the difference between the short-run and long-run responses to trade liberalization. In the short run, the number of firms is constant and, because of lags in establishing a presence in foreign markets, there is little downward pressure on mark-ups. In the long run, the number of firms adjusts and mark-ups fall. This is exactly what we are finding. To see this, let's translate the above claims into the language of our model. In the CES model, output per firm is fixed so that $Q_{j t}$ is proportional to the number of firms. (See the discussion following equation 2.) Thus, in the short run $Q_{j t}$ is constant (exogenous) and in the long run $Q_{j t}$ is variable (endogenous). Now consider $\sigma$. It has often been observed that in the CES model $\sigma$ is forced to carry the burden of being both a demand parameter and a measure of scale or mark-ups. (The mark-up of price over marginal cost is $\sigma /[\sigma-1]$. Note that this is decreasing in $\sigma$.) Instead 
of thinking of $\sigma$ as a demand parameter, focus instead on its interpretation as an inverse measure of the mark-up. Then we expect $\sigma$ to be larger in the long run than in the short run. This is exactly what we find in table 4 . When $Q_{j t}$ is endogenous (which we interpret as the long run), $\widehat{\sigma}$ is large (which we interpret as a low mark-up). Indeed, in the short run with $Q_{j t}$ exogenous and $\widehat{\sigma}=5.57$, the mark-up is 22 percent. In the long run with $Q_{j t}$ endogenous and with $\widehat{\sigma}=8.35$, the mark-up falls to 13 percent. If our interpretation is correct, our results offer a new and dynamic window on the hypothesis of imports as a market-disciplining device. ${ }^{4}$

\section{Trade Liberalization and Compensating Variation}

Most econometric work in international trade focusses on predicting trade flows, not welfare gains. That the two are not the same should be obvious. For example, when the $\sigma_{g}$ are very large, trade liberalization leads to large changes in trade flows with almost no implications for welfare. Our estimates of $\sigma_{g}$ together with data on expenditure shares $\alpha_{g}$ completely characterize the utility function $U_{i}=\Pi_{g=1}^{G}\left(U_{g i}\right)^{\alpha_{g}}$ where $U_{g i}$ is defined in equation (1). (As before, we continue to set the $\delta_{g i j}$ to unity.) It is not difficult to find an expression for the indirect utility function $V_{i}\left(Y_{i}, \tau \mid\left\{\sigma_{g}\right\}_{\forall g}\right)$. It depends on, among other things, income $Y_{i}$, the vector of tariffs worldwide $\tau \equiv\left\{\tau_{g i j}\right\}_{\forall g i j}$, and the elasticities of substitution $\sigma_{g}$. Note that for ease of exposition we have dropped time subscripts and re-introduced industry subscripts $g$. Let $C V_{i}$ be the compensating variation associated with a fall in tariffs from $\tau$ to $\tau^{0}$. We define $C V_{i}$ as the percentage of income $Y_{i}$ that country $i$ is willing to pay in order to move from a high-tariff regime $\tau$ to a low-tariff regime $\tau^{0}$. That is, $C V_{i}$ satisfies

$$
V_{i}\left(Y_{i}, \tau \mid\left\{\sigma_{g}\right\}_{\forall g}\right)=V_{i}\left(\left(1-C V_{i}\right) Y_{i}, \tau^{0} \mid\left\{\sigma_{g}\right\}_{\forall g}\right) .
$$

\footnotetext{
${ }^{4} \mathrm{~A}$ feature of the $\widehat{\sigma}_{\mathrm{IV}}$ that we have not commented on is their large standard errors. Part of this is the result of eliminating two of the five years of data. We already saw in column 6 of table 2 how eliminating the first year of data doubles the ML standard error. Another contributor to large standard errors may be the poor finite sample properties of standard errors based on asymptotic approximations. Indeed, the column 2 standard errors are very suspicious. Note that our estimates of standard errors based on hessians are more stable. For example, the column 2 score-based standard error of 12.34 falls to a more sensible hessian-based standard error of 4.03. Hausman tests using hessian-based covariance matrices always reject endogeneity.
} 
It is straightforward to show that with the normalization $\sum_{g} \alpha_{g}=1$,

$$
C V_{i}\left(\left\{\sigma_{g}\right\}_{\forall g}\right)=1-\prod_{g} x_{g i}\left(\sigma_{g}\right)
$$

where

$$
x_{g i}\left(\sigma_{g}\right) \equiv\left(\frac{\Sigma_{j}\left(\tau_{g i j}^{0}\right)^{1-\sigma_{g}} Q_{g j}}{\Sigma_{j}\left(\tau_{g i j}\right)^{1-\sigma_{g}} Q_{g j}}\right)^{\alpha_{g} /\left(1-\sigma_{g}\right)}
$$

The $\sigma_{g}$ are not known. However, we have estimated their means and variances (see table 10 below) and know that their asymptotic distribution is normal. This information fully characterizes the asymptotic probability density functions of the $\widehat{\sigma}_{g}$. Denote these densities by $\widehat{f}_{g}$. Since the $\widehat{\sigma}_{g}$ were estimated separately for each industry, we assume that they are independently distributed. This gives us all the information we need to estimate the mean and variance of $C V_{i}$.

From equations (17)-(18) and the independence of the $\widehat{\sigma}_{g}$,

$$
\mathbf{E}\left[C V_{i}\left(\left\{\widehat{\sigma}_{g}\right\}_{\forall g}\right)\right]=1-\Pi_{g} \mathbf{E}\left[x_{g i}\left(\widehat{\sigma}_{g}\right)\right] .
$$

where

$$
\mathbf{E}\left[x_{g i}\left(\widehat{\sigma}_{g}\right)\right]=\int_{-\infty}^{\infty} x_{g i}(\sigma) \widehat{f}_{g}(\sigma) d \sigma .
$$

Calculation of $\mathbf{E}\left[C V_{i}\left(\left\{\widehat{\sigma}_{g}\right\}_{\forall g}\right)\right]$ therefore involves the numerical integration of this integral for each industry $g=1, \ldots, 28$. In fact, we can do slightly better by imposing the a priori constraint $\sigma_{g}>1$ and using the conditional expectation

$$
\mathbf{E}\left[x_{g}\left(\widehat{\sigma}_{g i}\right)\right]=\int_{1}^{\infty} x_{g i}(\sigma) \widehat{f}_{g}(\sigma) d \sigma / \int_{1}^{\infty} \widehat{f}_{g}(\sigma) d \sigma .
$$

(We do not bother introducing notation to distinguish the respective $\mathbf{E}$ operators in equations 20 and 21.) We will report results based on equation (21) rather than equation (20), though as a practical matter it makes very little difference which we use.

We are also interested in the variance of $C V_{i}\left(\left\{\widehat{\sigma}_{g}\right\}_{\forall g}\right)$. This is just

$$
\mathbf{V}\left[C V_{i}\left(\left\{\widehat{\sigma}_{g}\right\}_{\forall g}\right)\right]=\Pi_{g} \mathbf{E}\left[\left[x_{g i}\left(\widehat{\sigma}_{g}\right)\right]^{2}\right]-\Pi_{g}\left[\mathbf{E}\left[x_{g i}\left(\widehat{\sigma}_{g}\right)\right]\right]^{2} .
$$

where $\mathbf{E}\left[\left[x_{g i}\left(\widehat{\sigma}_{g}\right)\right]^{2}\right]=\int_{1}^{\infty}\left[x_{g i}\left(\widehat{\sigma}_{g}\right)\right]^{2} \widehat{f}_{g}(\sigma) d \sigma / \int_{1}^{\infty} \widehat{f}_{g}(\sigma) d \sigma$. Thus, not only can we estimate expected compensating variation, we can also attach a standard error to the expectation. 
Table 5. Average Tariff Rates

\begin{tabular}{|c|c|c|c|c|c|}
\hline \multirow{5}{*}{ 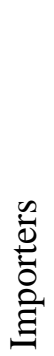 } & & \multicolumn{4}{|c|}{ Exporters } \\
\hline & & \multicolumn{2}{|c|}{36 Countries } & \multicolumn{2}{|c|}{14 Countries } \\
\hline & & 1972 & 1992 & 1972 & 1992 \\
\hline & 36 Countries & $12 \%$ & $5 \%$ & $12 \%$ & $5 \%$ \\
\hline & 14 Countries & $7 \%$ & $2 \%$ & $6 \%$ & $2 \%$ \\
\hline
\end{tabular}

Estimates of the welfare gains from trade liberalization $\left(C V_{i}\right)$ have appeared in the computable general equilibrium literature, but rarely in the econometric literature. Estimates of uncertainty about the expected welfare gains from trade liberalization (standard errors for $\left.\mathbf{E}\left[C V_{i}\right]\right)$ are even rarer. ${ }^{5}$

Since compensating variation depends critically on the level of tariffs, table 5 reports bilateral tariff rates for our trading partners. In 1992, the average tariff applied by our 14 importers against other members of this group was a very low 2 percent. This was down from 6 percent in 1972. The average tariff rate applied by our 36 countries against each other was 5 percent in 1992. Table 9 of Appendix D provides more detail about the structure of bilateral tariffs in $1992 .^{6}$

We begin by considering what would happen to welfare if our 14 importers formed a free trade area. That is, suppose that our 14 importing countries dropped all tariffs against each other, but retained existing tariffs against countries outside the group of 14 . Table 6 reports the $\mathbf{E}\left[C V_{i}\right]$ and $\mathbf{V}\left[C V_{i}\right]$ for this scenario. The welfare gains from this free

\footnotetext{
${ }^{5}$ The only study we know of that includes standard errors is the Berry et al. (1999) automotive study.

${ }^{6}$ There remains the question of what to use for $\alpha_{g}$ in equation (18). The most sensible measure readily available is value-added shares. Let $g=0$ denote non-manufacturing. From the 1992 World Development Indicators, world non-manufacturing value added as a share of world gross domestic product is 0.77 . We take this as our value of $\alpha_{0}$. For manufacturing industries, we do not have value added by detailed industry. Instead, we assume that value added is proportional to output. Specifically, define $Q_{g} \equiv \sum_{j=1}^{36} Q_{g j, 1992}$ and $Q \equiv \sum_{g=1}^{28} Q_{g}$. Then $\alpha_{g}=\left(1-\alpha_{0}\right) Q_{g} / Q$ for $g=1, \ldots, 28$. For non-manufacturing, we assume that tariffs are zero both before and after liberalization.
} 
Table 6. Compensating Variation for the 14 Importing Countries

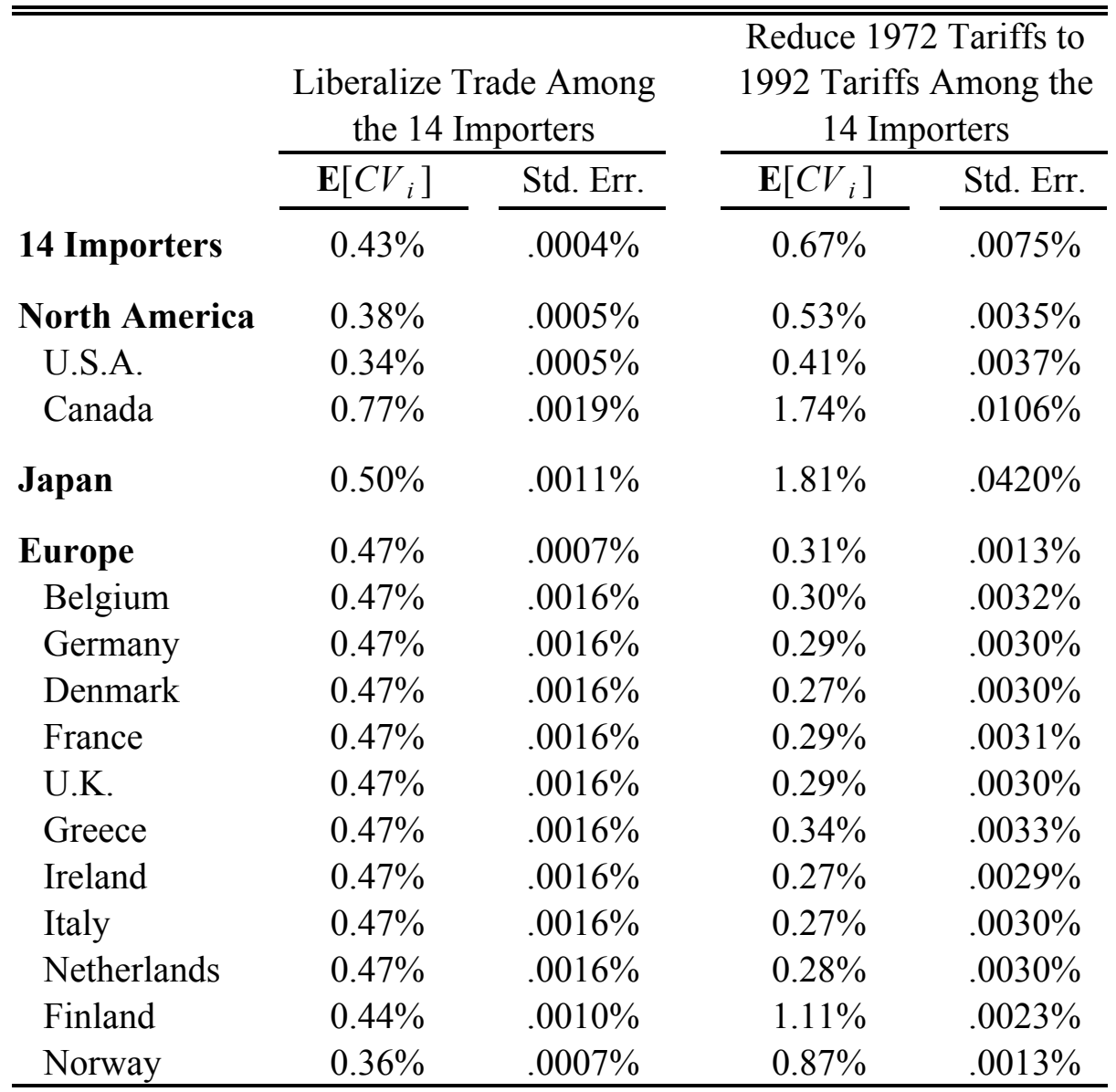

Notes: Compensating variation is expressed as a percentage of a region's 1992 income. North America consists of Canada and the United States. Europe consists of the 11 countries listed below it.

trade area are equivalent to 0.43 percent of the group's 1992 income. $^{7}$ All countries gain with Canada gaining the most (0.77 percent) and the United States gaining the least (0.34 percent). These are surprisingly large numbers given how low tariffs were in 1992. The table also presents standard errors on the compensating variation associated with our international tariff reductions. To our knowledge, this is a first. Standard errors translate the tension between the data and the model into uncertainty about the gains from trade.

\footnotetext{
${ }^{7}$ We have not yet derived an expression for the mean and variance of the compensating variation for a group of countries such as North America in table 6. Let $C V_{A}\left(\left\{\sigma_{g}\right\}_{\forall g}\right)=\sum_{i \in A} s_{i}^{\prime} C V_{i}\left(\left\{\sigma_{g}\right\}_{\forall g}\right)$ where $s_{i}^{\prime} \equiv s_{i} / \sum_{k \in A} s_{k}$ be the income-weighted compensating variation of country group $A$. Then the expected welfare gain for country group $A$ is $\mathbf{E}\left[C V_{A}\left(\left\{\sigma_{g}\right\}_{\forall g}\right)\right]=\sum_{i \in A} s_{i}^{\prime} \mathbf{E}\left[C V_{i}\left(\left\{\sigma_{g}\right\}_{\forall g}\right)\right]$. Calculating the variance of the country group welfare gains is more complicated. We approximate its theoretically correct expression with $\mathbf{V}\left[C V_{A}\left(\left\{\sigma_{g}\right\}_{\forall g}\right)\right]=\Sigma_{i \in A} s_{i}^{2} \mathbf{V}\left[C V_{i}\left(\left\{\sigma_{g}\right\}_{\forall g}\right)\right]$.
} 
The reason for the tight standard errors will become clear shortly.

Table 6 also shows a second scenario. Suppose that in 1972 our 14 importing countries had reduced tariffs against each other to their 1992 levels while leaving unchanged their tariffs against countries outside the group of 14 . (For this scenario, $Q_{g j t}$ in the denominator of equations 17-18 is drawn from 1972 data.) From the right-hand-side panel of table 6, welfare would have risen by the equivalent of 0.67 percent of 1972 income. Thus, historical tariff reductions are estimated to have raised world welfare substantially. What is particularly interesting is the distribution of gains. Japan and Canada are by far the biggest winners.

Table 7 shows the scenario of eliminating 1992 tariffs among all 36 trading partners. The compensating variation of 1.80 percent is much larger than the 14-country result of 0.44 percent. Countries such as pre-NAFTA Mexico and import-substituters such as India, Argentina, and Brazil stand out as the big winners. The gains to other middle-income countries in Latin America and Asia are also striking. Even the United States gains by 0.58 percent.

Figure 2 is a useful tool for understanding the features of the model and the data that are driving our welfare estimates. To produce the figure, we aggregated manufacturing into a single sector so that it is a function of only a single elasticity of substitution $\sigma$. Figure 2 reports $C V_{\text {WORLD }}$ as a function of $\sigma$ for each of the three scenarios reported in tables 6 and 7. Three things stand out.

First, for the scenario of eliminating 1992 tariffs among our 14 importers, the EC $V_{\text {WORLD }}$ curve is flat. This explains the small standard errors for this case. No matter what we choose for the $\widehat{\sigma}_{g}$ and their standard errors, the mean of EC $V_{\text {WORLD }}$ will be about 0.4 percent and will have a small standard error. This explains why we have not yet said what we used for the $\widehat{\sigma}_{g}$ and their standard errors. We used our baseline ML specification (defined in table 2) applied at the 3-digit ISIC industry level. The estimates are reported in table 10 of Appendix E. Using the IV estimates yields virtually identical results. For example, EC $V_{\text {WORLD }}$ is 0.44 percent when the $\widehat{\sigma}_{g}$ are estimated using the IV 
Table 7. Compensating Variation for the 36 Exporting Countries

\begin{tabular}{|c|c|c|c|c|c|}
\hline & \multicolumn{2}{|c|}{$\begin{array}{c}\text { Liberalize Trade Among } \\
\text { the } 36 \text { Exporters }\end{array}$} & & \multicolumn{2}{|c|}{$\begin{array}{c}\text { Liberalize Trade Among } \\
\text { the } 36 \text { Exporters }\end{array}$} \\
\hline & $\mathbf{E}\left[C V_{i}\right]$ & Std. Err. & & $\mathbf{E}\left[C V_{i}\right]$ & Std. Err. \\
\hline 36 Exporters & $1.80 \%$ & $.0084 \%$ & North America & $0.95 \%$ & $.0013 \%$ \\
\hline \multirow[t]{2}{*}{14 Importers } & $0.67 \%$ & $.0010 \%$ & Mexico & $3.91 \%$ & $.0081 \%$ \\
\hline & & & Canada & $1.16 \%$ & $.0023 \%$ \\
\hline Europe & $0.72 \%$ & $.0009 \%$ & U.S.A. & $0.58 \%$ & $.0013 \%$ \\
\hline Austria & $1.26 \%$ & $.0075 \%$ & & & \\
\hline Portugal & $1.11 \%$ & $.0023 \%$ & Asia & $3.30 \%$ & $.0302 \%$ \\
\hline Spain & $1.08 \%$ & $.0024 \%$ & India & $7.66 \%$ & $.1121 \%$ \\
\hline Sweden & $0.68 \%$ & $.0009 \%$ & Thailand & $4.78 \%$ & $.0644 \%$ \\
\hline EU-8 & $0.67 \%$ & $.0025 \%$ & Sri Lanka & $4.23 \%$ & $.0174 \%$ \\
\hline Greece & $0.67 \%$ & $.0025 \%$ & Indonesia & $3.31 \%$ & $.0350 \%$ \\
\hline Finland & $0.67 \%$ & $.0023 \%$ & Malaysia & $2.96 \%$ & $.0083 \%$ \\
\hline \multirow[t]{2}{*}{ Norway } & $0.51 \%$ & $.0013 \%$ & Korea & $2.81 \%$ & $.0266 \%$ \\
\hline & & & Japan & $0.76 \%$ & $.0040 \%$ \\
\hline Latin America & $5.00 \%$ & $.0216 \%$ & Singapore & $0.31 \%$ & $.0047 \%$ \\
\hline Argentina & $7.15 \%$ & $.0353 \%$ & Hong Kong & $0.00 \%$ & $.0000 \%$ \\
\hline Brazil & $5.06 \%$ & $.0346 \%$ & & & \\
\hline Chile & $3.85 \%$ & $.0041 \%$ & Other & & \\
\hline Venezuela & $3.46 \%$ & $.0089 \%$ & Tunisia & $5.11 \%$ & $.0074 \%$ \\
\hline \multirow[t]{3}{*}{ Ecuador } & $3.11 \%$ & $.0041 \%$ & Morocco & $3.97 \%$ & $.0092 \%$ \\
\hline & & & New Zealand & $1.86 \%$ & $.0046 \%$ \\
\hline & & & Australia & $1.73 \%$ & $.0054 \%$ \\
\hline
\end{tabular}




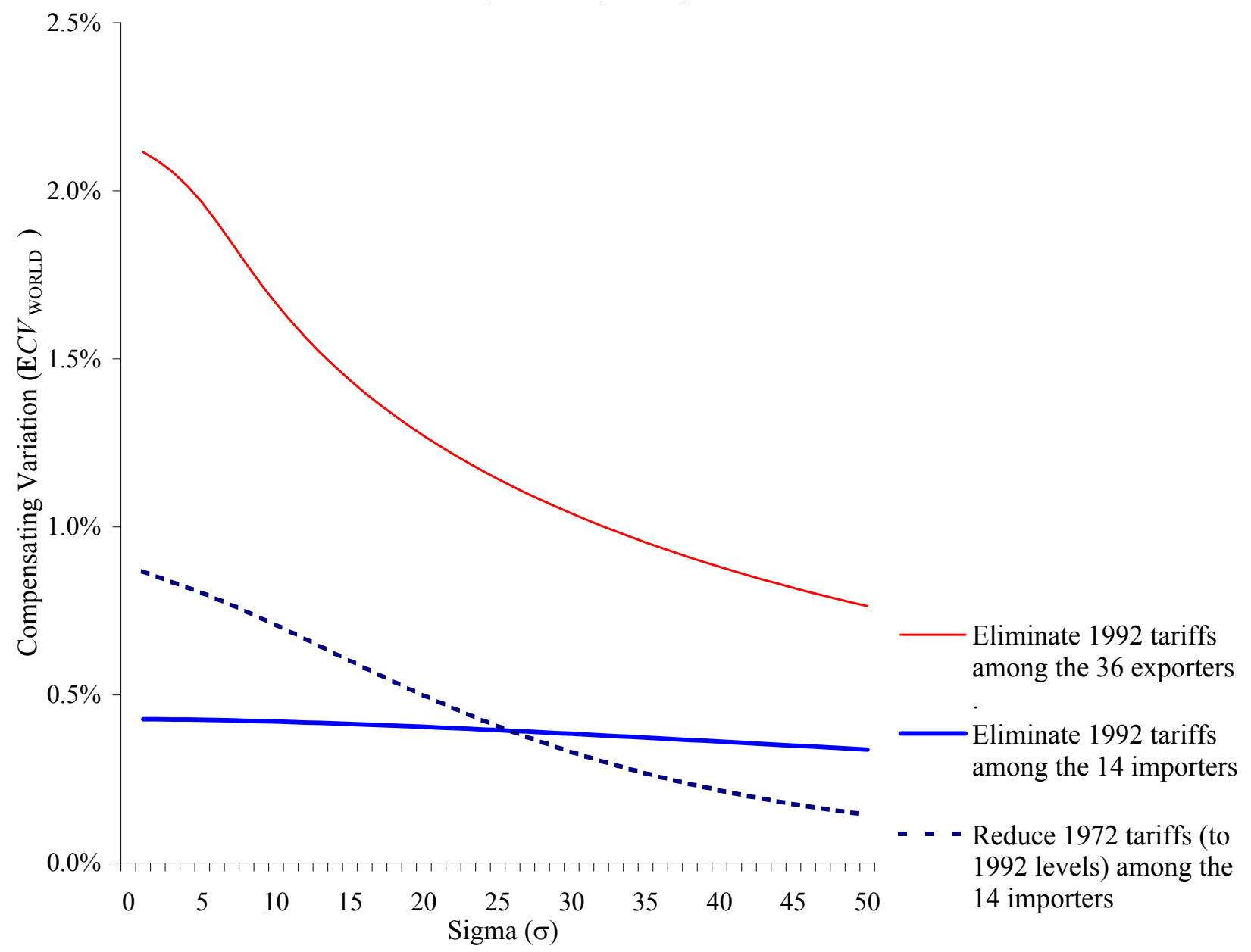

Figure 2. World Compensating Variation: EC $V_{\text {WORLD }}$ vs. $\sigma$

method described in column 5 of table 4 (bottom panel).

Second, for the other two scenarios, the EC $V_{\text {WORLD }}$ curve is concave in the range of the estimated $\sigma_{g}$. This turns out to imply that the results for $\mathbf{E} C V_{\text {WORLD }}$ are again independent of whether we use the ML or IV estimates of the $\sigma_{g}$. The IV estimates yield larger $\widehat{\sigma}_{g}$ which imply a smaller EC $V_{\text {WORLD }}$. However, the IV estimates also yield much larger standard errors on the $\sigma_{g}$. By the concavity of ECV $V_{\text {WORLD }}$, the larger standard errors imply a larger EC $V_{\text {WORLD }}$. As an empirical matter, these two effects cancel so that we obtain the same $\mathrm{E} C V_{\text {WORLD }}$ for both the ML and IV estimates.

Third, the $\operatorname{EC} V_{\text {WORLD }}(\sigma)$ are downward sloping. This represents a major problem with the interface between the theory and the data, a problem that we suspect reflects the dominance of the theory over the data. The slope of $\operatorname{EC} V_{\text {WORLD }}(\sigma)$ is determined by 
two effects. To see this, drop $g$ subscripts, re-write the equation (1) sub-utility function as $\widetilde{U}_{i}(\sigma, q(\sigma))$ to reflect the fact that $\sigma$ enters utility both as a parameter and, via equation (2), as a determinant of output. There are thus two effects of an increase in $\sigma$ : (1) the pure preference effect, $\partial \widetilde{U}_{i} / \partial \sigma$ holding $q$ fixed and (2) the general equilibrium effect $\left(\partial \widetilde{U}_{i} / \partial q\right) /(\partial q / \partial \sigma)$. The signs of these two effects are in general ambiguous. However, they take on their expected signs when evaluated at any most-favoured nation (MFN) tariff rate i.e., at any $\tau_{i j}$ that is independent of $j$. Specifically, the pure preference effect is negative (a rise in $\sigma$ reduces love of variety) and the general equilibrium effect is positive (a rise in $\sigma$ raises $q(\sigma)$ and thus raises consumer surplus). The downward sloping lines in figure 2 show that the pure preference effect dominates the core general equilibrium effects of the model. This is deeply disturbing. It also means that sensitivity analysis reporting how compensating variation depends on $\sigma$ is misleading unless the pure preference and general equilibrium effects are separated out. This is not currently done in the CGE literature, but should be done in the future.

The gains from trade just reported are large. However, they are probably lower bounds on the world gains implied by the monopolistic competition model. There are three reasons for this. First, although we have endogenized the $Q_{j t}$ so that the level and international distribution of production is endogenous, the only way this shows up in the estimates of compensating variation is via the estimates of the $\widehat{\sigma}_{g}$. Since our estimates of compensating variation are ex post not all that sensitive to whether ML or IV estimates of the $\widehat{\sigma}_{g}$ are used, it is hard to argue ex post that we are capturing the welfare losses that result from an inefficient worldwide allocation of production. Thus, in textbook fashion we are likely only estimating the consumption effect i.e., the welfare losses that arise because consumers face prices that are higher than producer prices. Second, by assuming a Cobb-Douglas upper-tier utility structure we have not allowed for gains due to substitution from non-tradeable to tradeable goods. Third, there are production effects that cannot be captured in a CES monopolistic competition model because the model implies that producer price and output levels are independent of the tariff. In a more general model, one might expect 
tariff reductions to lower producer prices and increase firm-level output.

To summarize, we have precisely estimated very large gains from tariff liberalization. Against this we have documented a number of problems which indicate that the precision of the estimates of compensating variation is likely driven more by the model than by the data. They also suggest a disturbing dominance of the pure preference effect over core general equilibrium effects.

\section{The Second Goal: Does the Model Do Violence to the Data?}

Until now the paper has dealt primarily with our first goal, namely, estimation of the welfare gains from trade. The analysis was conducted on the assumption that the CES monopolistic competition model is correctly specified. For the remainder of the paper we turn to our second goal of questioning this assumption. Figure 1 above painted a picture of a model that performs remarkably well. Is this really the case or are the results being driven by unexpected features of the data or model? It is to this question that the full weight of econometric sensitivity analysis can be brought to bear. In examining the model for mis-specification our focus is on the model's three key predictions.

1. $\ln M_{i j t}$ depends linearly on $\ln Q_{j t}$ primarily via the data identity $\Sigma_{i} M_{i j t}=Q_{j t}$. (See equation 4.) Note that this prediction has little economic content.

2. $\ln M_{i j t}$ depends linearly on $\ln s_{i t}$ via the homotheticity of demand. This is a behavioural prediction.

3. $\ln M_{i j t}$ depends linearly on $\ln \Phi_{i j t}$ via CES price effects and general equilibrium interactions. Referring to the equation (6) definition of $\Phi_{i j t}$ (and dropping $g$ subscripts), the numerator of $\Phi_{i j t}$ is just $\tau_{i j t}^{-\sigma} / \Sigma_{k} \tau_{i k t}^{1-\sigma} Q_{k t}$ which is closely related to the CES price index and enters the model behaviourally via utility maximization. The denominator of $\Phi_{i j t}$ is $\Sigma_{n} s_{n t} \tau_{n j t}^{-\sigma} / \Sigma_{k} \tau_{n k t}^{1-\sigma} Q_{k t}$ which is related to a market potential function and captures the most important general equilibrium relationships of the model. $\Phi_{i j t}$ 
therefore describes the deepest behavioural and general equilibrium aspects of the model. It is rightly the focus of this paper.

We examine these three implications in detail.

\section{The Price Term $\Phi_{i j t}$}

Figure 3 provides three plots that shed light on the performance of the price term. The top panel plots $\ln M_{i j t}$ against $\ln s_{i t} \Phi_{i j t} Q_{j t}$ and reinforces how wonderfully the model fits. The middle panel plots $\ln M_{i j t}$ against $\ln \Phi_{i j t}$ and suggests that only a small part of the good fit is being driven by the price term. One might think that a bivariate plot of this form is misleading because of the covariances between the price, income, and output terms. To control for this, the bottom panel of figure 3 plots $\ln \left(M_{i j t} / s_{i t} Q_{j t}\right)$ against $\ln \Phi_{i j t}$. The fit is now tighter. The plots also report $R^{2}$ statistics derived from a bivariate regression of the vertical-axis variable against the horizontal-axis variable. ' $R{ }^{2}$ All' is the $R^{2}$ from the bivariate regression. For example, in the bottom panel the price term explains 16 percent of the sample variation in $\ln \left(M_{i j t} / s_{i t} Q_{j t}\right)$.

In these plots and those to follow, $\ln \Phi_{i j t}=\Phi_{i j t}(\widehat{\sigma})$ is evaluated at $\widehat{\sigma}=5.30$ taken from our table 2 ML baseline estimate. Similar results hold for the IV estimates of $\widehat{\sigma}$ as well. Since the baseline estimate uses a GLS estimator, all data are scaled by the estimated standard error of the residuals $\varepsilon_{i j t}$ i.e., by the $\psi_{i j}$ defined at the start of section 4 . Each plot has 2,520 observations. This corresponds to 504 country pairs (14 imports $\times 36$

exporters) in each of 5 years $(1972,1977,1982,1987$, and 1992). Note that we have returned to working with aggregate manufacturing.

It is frequently argued that love-of-variety models are inappropriate for the trade of poorer countries. To examine this, we split the sample into two groups. The rich group includes the 20 countries that are in our group of 14 importers and/or have 1982 World Bank per capita gross domestic product (GDP) in excess of $\$ 6,000$. The poor group consists of the remaining 16 countries in our sample. Each plot in figure 3 has three types of markers: (1) a ' $o$ ' for domestic observations $(i, i)$ where in our data $i$ is always a rich 

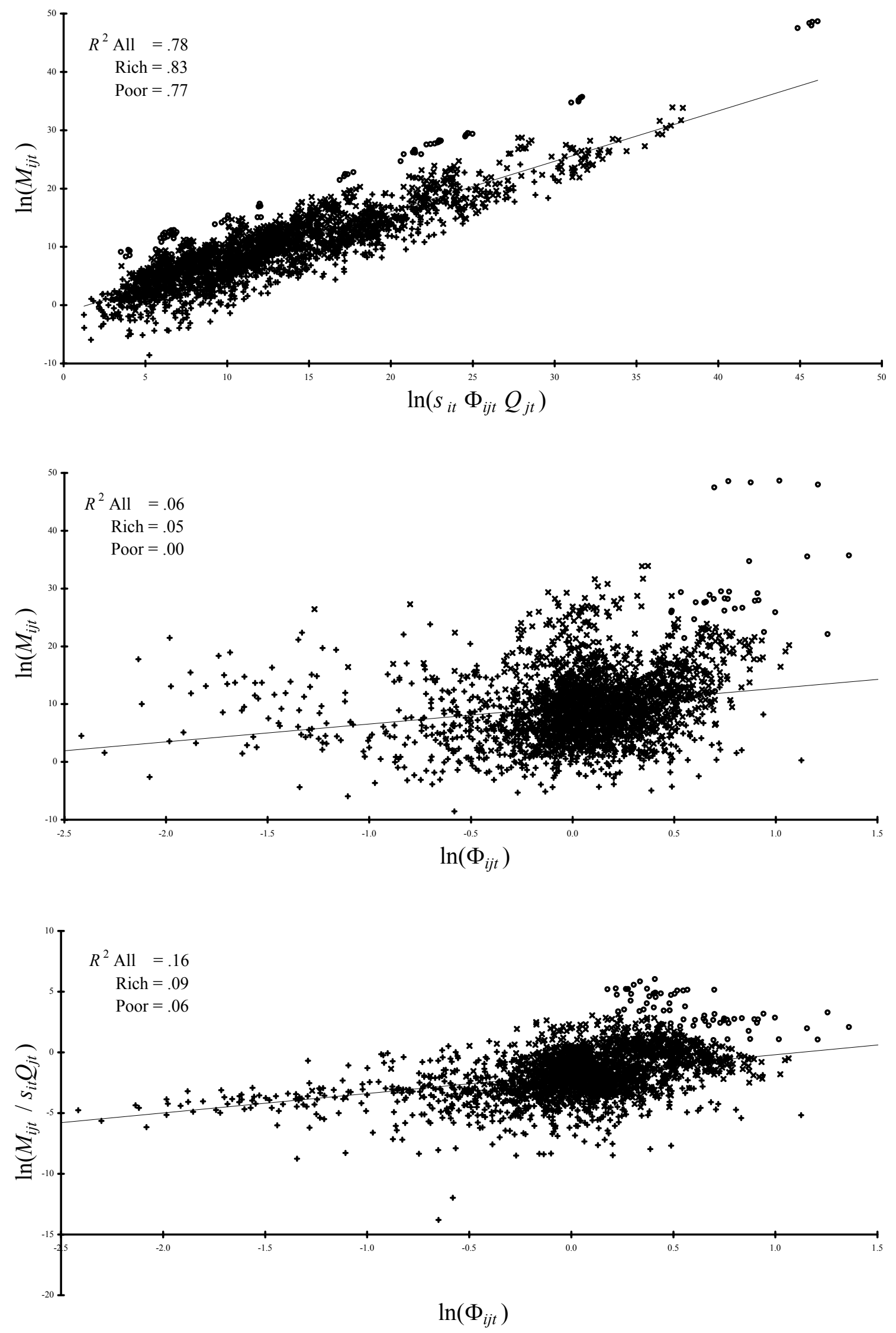

Figure 3. The Price Term in Levels (1972, 1977, 1982, 1987, and 1992) 
country; (2) an ' $x$ ' for trade between rich importers and rich exports; and, (3) a ' + ' for trade between rich importers and poor exporters. ' $R{ }^{2}$ Rich' is the $R^{2}$ from a bivariate regression involving only ' $\mathrm{x}$ ' or rich-rich observations. ' $R{ }^{2}$ Poor' is the $R^{2}$ from a bivariate regression involving only ' + ' or rich-poor observations. Is there any evidence that the model performs better for rich countries than for poor countries? The answer is no: the ' $R$ 'Rich' statistics of figure 3 are barely larger than the ' $R$ ' Poor'statistics.

We have argued hard for the importance of separating out within country-pair sample variation from between country-pair sample variation. Our contention is that the within variation is cleaner for estimating price effects because it requires fewer assumptions about the similarity of country pairs. To examine this cleaner 'within' sample variation we differenced the data using a 20-year difference. This leaves us with 504 observations, one for each country pair. The differenced data are plotted in figure 4 . For example, the top panel plots $\Delta \ln M_{i j t} \equiv \ln M_{i j 1992}-\ln M_{i j 1972}$ against $\Delta \ln s_{i t} \Phi_{i j t} Q_{j t} \equiv \ln s_{i 1992} \Phi_{i j 1992} Q_{j 1992}-$ $\ln s_{i 1972} \Phi_{i j 1972} Q_{j 1972}$. Several facts emerge. Comparing the top panels of figures 3 and 4 , the model does not fit the differenced data nearly as well as the levels data. This is reflected in the ' $R{ }^{2}$ All' statistic which has fallen from 0.78 to only 0.21 . Notice from the ' $R{ }^{2}$ Poor' $^{\prime}$ statistic of 0.30 that almost all of the good fit is being driven by rich-country imports from poor countries. This is reminiscent of Hummels and Levinsohn (1995).

The two lower panels of figure 3 show the real kicker. The price term $\Phi_{i j t}$ literally contributes nothing to the analysis of changing trade patterns. This is reflected in the ' $R{ }^{2}$ All' statistics of 0.02 and 0.01 . This is a deeply disturbing result. The CES monopolistic competition model has been used extensively for assessing the welfare gains from trade. Yet if one asks "For a given pair of countries, do changes in tariffs over time predict changes in bilateral trade flows?" the answer from this model is a resounding "No." Restated, the data are completely at odds with the model's core behavioural and general equilibrium predictions about the impact of trade liberalization. 

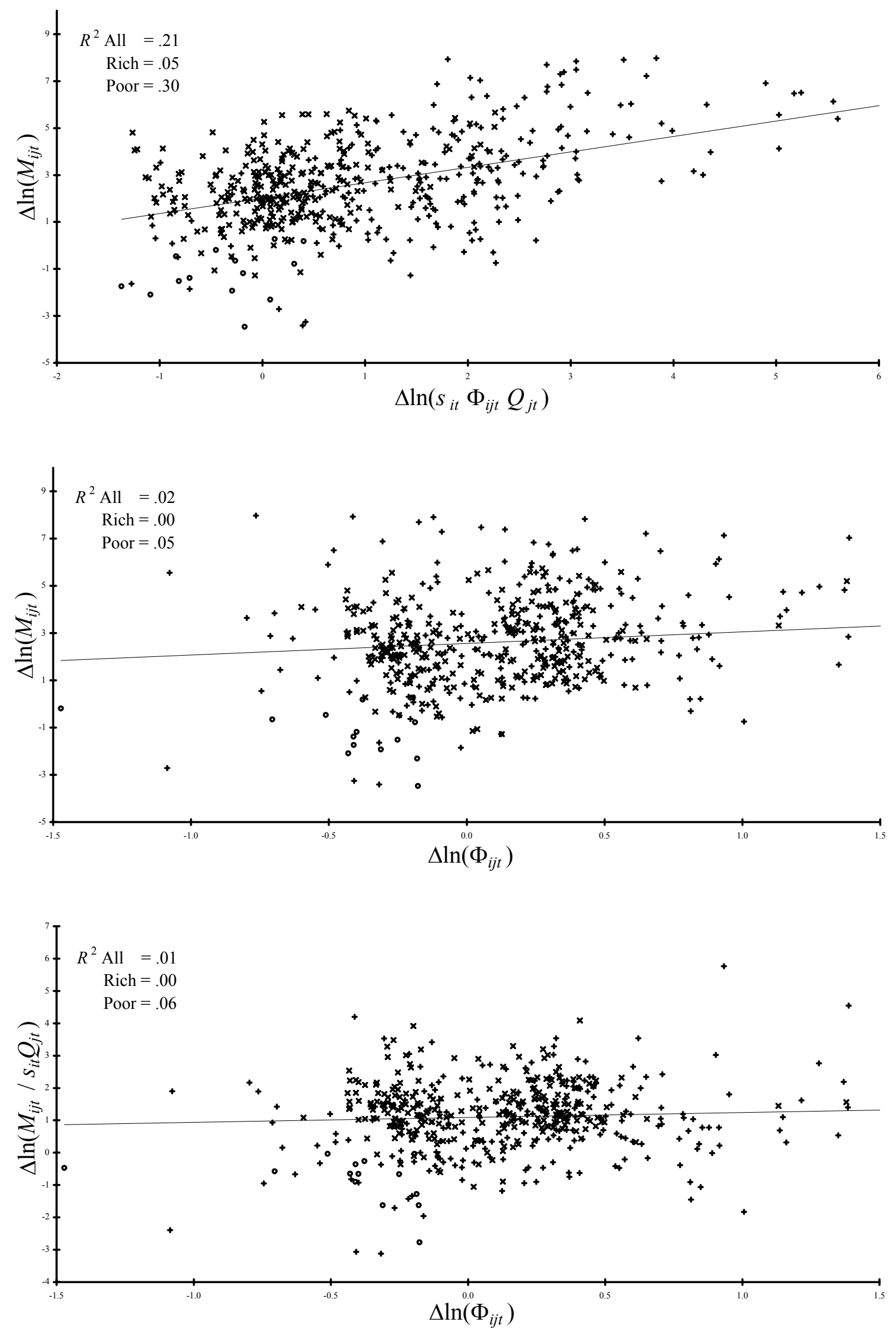

Figure 4. The Price Term in Changes: 1992 - 1972 

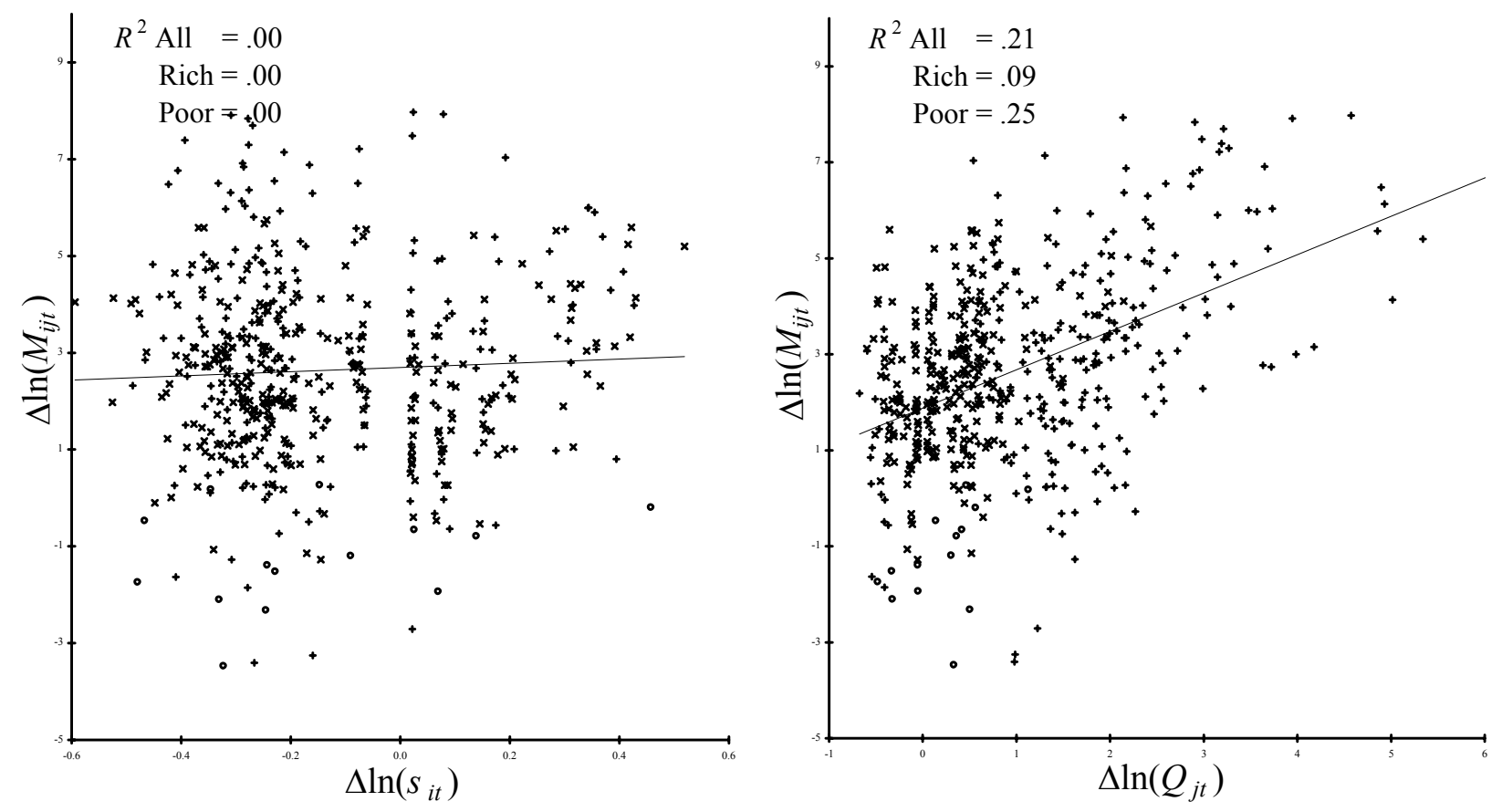

Figure 5. The Income $\left(s_{i t}\right)$ and Data-Identity $\left(Q_{j t}\right)$ Terms in Changes: $1992-1972$

\section{Income and Data-Identity Terms}

The income $\left(s_{i t}\right)$ and data-identity $\left(Q_{j t}\right)$ terms have been examined directly or indirectly by a large number of researchers. Indeed, the model $\ln M_{i j t}=\ln s_{i t}+\ln Q_{j t}$ is very much a gravity equation. One therefore needs a good reason for revisiting the model. We think we have one. The left-hand panel of figure 5 plots $\Delta \ln M_{i j t} \equiv \ln M_{i j 1992}-\ln M_{i j 1972}$ against $\Delta \ln s_{i t} \equiv \ln s_{i 1992}-\ln s_{i 1972}$. The relationship is weak: the ' $R^{2}$ All' statistic is 0.00 . This means that the income term explains absolutely none of the within country-pair sample variation. We do not think that most researchers realize this. Jensen (2000) is an exception. ${ }^{8}$

The right-hand panel of figure 5 plots $\Delta \ln M_{i j t}$ against $\Delta \ln Q_{j t} \equiv \ln Q_{j 1992}-\ln Q_{j 1972}$. The striking feature of the plot is that it is very similar to the figure 4 plot of $\Delta \ln M_{i j t}$ against $\Delta \ln s_{i t} \Phi_{i j t} Q_{j t}$. To confirm this, note that the ' $R^{2}$ All' statistics of figure 5 (left-hand plot) and figure 4 (top plot) are identical. This means that almost all of the good fit of the CES monopolistic competition model comes from the data-identity term $Q_{j t}$. Again, the

\footnotetext{
${ }^{8}$ We are grateful to Rob Feenstra for pointing out that an earlier draft contained some odd gravity results that needed to be investigated.
} 
predictive success is highest for observations involving rich-country imports from poor countries. The ' $R^{2}$ Poor' statistic is 0.25 . This raises a key question as to why small producers export a little to all partners rather than exporting everything to just a small group of partners. What is the economic channel through which this comes about? The most obvious possibility is that these small producers have a comparative cost advantage in some niche product demanded in small amounts by all importers. But what is the source of this comparative cost advantage and what is the niche? The CES model is about such niches, but it stretches the model to say that every small producer in every poor country produces a niche variety. The results of Hallak (2001) and Schott (2001) suggest that quality is important. Alternatively, it may be a Ricardian story. Of course, the two are not neatly separable. For example, Brazil has a Ricardian cost advantage in cheap low-quality steel rails, but not in the high-quality steel sheets needed for automobile panels. Clearly, more work is needed to understand this issue. Understanding the process generating the $Q_{j t}$ is apparently more crucial for understanding trade flows than previously recognized in the empirical literature surrounding these type of equations.

To summarize, recall that the deep behavioural and general equilibrium aspects of the model are captured by the price and income terms $\left(\Phi_{i j t}\right.$ and $\left.s_{i t}\right)$. Yet these terms contribute only modestly to explaining the total sample variation and explain absolutely none of the within country-pair sample variation. The economics of the CES monopolistic model contributes much less to understanding trade flows than has previously been recognized. The data-identity term $\left(Q_{j t}\right)$ drives most of the within country-pair sample fit. As such, much more attention must be given to understanding the location-of-production aspects of the model.

\section{The Between Country-Pair Sample Variation: Fixed Effects}

The fixed effects $\lambda_{i j}$ measure the average prediction error of each country pair. One explanation of this prediction error is that there are many more trade costs than just the tariffs and discriminatory internal taxes that we are measuring. Most obvious of these are the 


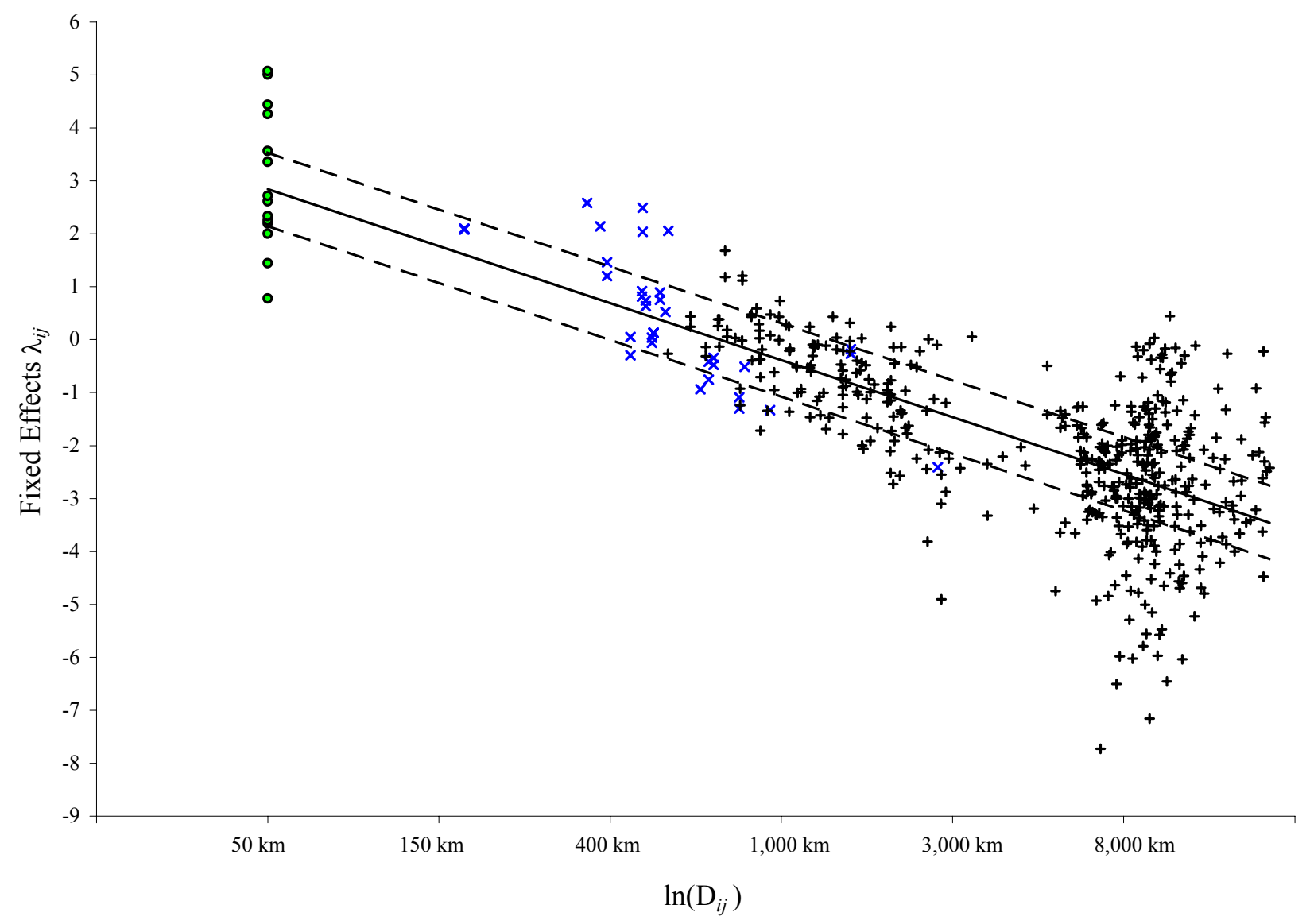

Note : To make the relationship between the fixed effects and distance look its strongest, we set $D_{i i}=55 \mathrm{~km}$ rather than $0 \mathrm{~km}$.

Figure 6. Distance $\left(\ln D_{i j}\right)$ vs. Country-pair Fixed Effects $\left(\lambda_{i j}\right)$

trade costs associated with distance $D_{i j}$ between trading partners. Lai (1999) introduced distance into our estimating equation by replacing $\tau_{i j t}$ with $\tau_{i j t} D_{i j}^{\alpha}$ in the expression for $\Phi_{i j t}$. However, he found that it did not much affect the results regarding tariffs. Since distance is time invariant it is natural to ask whether distance enters the estimating equation via the time-invariant $\lambda_{i j}$ rather than via the $\Phi_{i j t}$.

Figure 6 plots the $\lambda_{i j}$ fixed effects against $\ln D_{i j} \cdot{ }^{9}$ To begin with, most of the $\lambda_{i j}$ are negative meaning that there is much less trade than is predicted by the theory. In the plot, 'o' denotes an $(i, i)$ observation, ' + ' denotes an observation for which $i$ and $j$ are adjacent,

\footnotetext{
${ }^{9}$ Data are from Antweiler (1995) and are based on the weighted average distance between all city pairs in the two countries $i$ and $j$. For example, if there are 2 cities in country $i$ and 3 cities in country $j$ then there are 6 city pairs. The weights used in aggregating the 6 city pairs are based on the populations of the cities. Only cities with population in excess of 1,000,000 are included in the calculations.
} 
and ' $x$ ' denotes all other observations. The overall impression conveyed by figure 6 is that the fixed effects are indeed explained by distance. There are, however, some caveats. First, the solid line is the regression line of $\lambda_{i j}$ on $\ln D_{i j}$. The dashed lines shift the regression line by $\pm \ln 2$, meaning that all observations outside the dashed lines involve predictions that are off by more than 100 percent. About half of the observations lie outside the 100 percent error lines. Second, consider the dispersion of the average prediction error $\exp \widehat{\lambda}_{i j}$ for different values of distance. There is a 74-fold dispersion in the prediction error for own-country observations $(i, i)$, a 146-fold dispersion in the prediction error for adjacent countries, and over a 1,000-fold dispersion in the prediction error for country pairs that are separated by distances of between 8,000 and 9,000 kilometres. These are large errors. Third, consider the 351 observations with $D_{i j}>5,000$. These represent 70 percent of the observations and so are in no sense a minor subsample. For this group, the $R^{2}$ from a regression of $\lambda_{i j}$ on $\ln D_{i j}$ is 0.0002 i.e., there is no relationship between the fixed effects and distance for this subsample. Thus, distance by itself far from explains all or even most of the country-pair sample variation.

\section{Specification Tests and Model Selection}

In the CGE literature there is no sense in which one can formally compare the performance of one model with another. Calibration ensures that both will fit the data exactly. (For a balanced discussion of this point, see Dawkins, Srinivasan and Whalley 2001.) Model comparison can be done in the econometric-based international trade literature, but rarely is. We now turn to filling this gap. Each row of table 8 presents an alternative model that will be compared to the CES monopolistic competition model. Row 1 is a distance model with two regressors, $\ln D_{i j}$ and $\left(\ln D_{i j}\right)^{2}$. (The models in rows 1-4 each have two regressors.) Row 2 is an income-similarity model that uses the products of country-pair GDPs $\left(Y_{i}\right)$ and PPP-adjusted per capita GDPs $\left(y_{i}\right)$. Row 3 is an endowments-based model. $L_{i}$ is country $i$ 's population, $H_{i}$ is the population that completed high school, and $K_{i}$ is capital stock. Data are in part from Summers and Heston (1991) and Barro and Lee 
Table 8. Non-Nested Hypothesis Testing (Specification Testing)

\begin{tabular}{|c|c|c|c|c|c|c|}
\hline \multirow[b]{4}{*}{ Row } & \multirow[b]{4}{*}{ Model } & \multicolumn{2}{|c|}{ MacKinnon's $P$-Statistic } & \multirow{2}{*}{\multicolumn{3}{|c|}{$\begin{array}{l}\text { Correlations of } \ln M_{i j t} \\
\text { with its prediction }\end{array}$}} \\
\hline & & \multirow{3}{*}{$\begin{array}{c}\mathrm{H}_{0}: \ln s_{i t} \Phi_{i j t} Q_{j t} \\
\mathrm{H}_{1}: X_{i j t} \beta \\
(1)\end{array}$} & \multirow{3}{*}{$\begin{array}{c}\mathrm{H}_{0}: X_{i j t} \beta \\
\mathrm{H}_{1}: \ln s_{i t} \Phi_{i j t} Q_{j t} \\
(2)\end{array}$} & & & \\
\hline & & & & Total & Within & Between \\
\hline & & & & (3) & $(4)$ & $(5)$ \\
\hline 1 & $\begin{array}{l}\ln D_{i j} \\
\left(\ln D_{i j}\right)^{2}\end{array}$ & 4.69 & 11.06 & 0.34 & 0.38 & 0.34 \\
\hline 2 & $\begin{array}{l}\ln \left(Y_{i t} Y_{j t}\right) /\left(Y_{i t}+Y_{j t}\right) \\
\ln \left(y_{i t} y_{j t}\right) /\left(y_{i t}+y_{j t}\right)\end{array}$ & 11.45 & 6.32 & 0.67 & 0.62 & 0.67 \\
\hline 3 & $\begin{array}{l}\left|H_{i t} / L_{i t}-H_{j t} / L_{j t}\right| \\
\left|K_{i t} / L_{i t}-K_{j t} / L_{j t}\right|\end{array}$ & 0.66 & 11.53 & -0.21 & 0.36 & -0.24 \\
\hline 4 & $\begin{array}{l}\left|H_{i t} / L_{i t}-H_{j t} / L_{j t}\right| \ln \left(s_{i t} Q_{j t}\right) \\
\left|K_{i t} / L_{i t}-K_{j t} / L_{j t}\right| \ln \left(s_{i t} Q_{j t}\right)\end{array}$ & 0.32 & 11.18 & 0.08 & 0.38 & 0.06 \\
\hline 5 & $\ln \tau_{i j t}$ & 2.93 & 9.42 & 0.31 & 0.38 & 0.32 \\
\hline 6 & $\ln \left(s_{i t} \Phi_{i j t} Q_{j t}\right)$ & & & 0.71 & 0.36 & 0.72 \\
\hline
\end{tabular}

Notes : 1) MacKinnon's non-nested $P$-statistic is asymptotically a $t$-statistic with over 2,000 degrees of freedom.

2) The 'Correlations' columns report the correlation between $\ln \left(M_{i j t}\right)$ and $X_{i j t} \beta$ where $X_{i j t}$ is described in the 'Model' column.

3) Each row is an alternative specification. $D_{i j}$ is the weighted distance between major cities in countries $i$ and $j, Y_{i t}$ is country $i$ 's GDP, $y_{i t}$ is $i$ 's per capita GDP, $H_{i t}$ is $i$ 's population that completed high school, $L_{i t}$ is $i$ 's labour force, and $K_{i t}$ is $i$ 's capital stock. All specifications are estimated using an AR(1) correction, but no GLS, fixed effect, or firstobservation corrections.

(1993). Row 4 follows the Evenett and Keller (2002) observation that a combination of monopolistic competition and factor endowments offers a better explanation of trade than either one separately. Row 5 is a naive tariff model.

Our specification test is MacKinnon's non-nested P-test (Davidson and MacKinnon, 1993). Column 1 of table 8 reports the $P$-statistic when the null is $\ln s_{i t} \Phi_{i j t} Q_{j t}$ and the 
alternative is the model listed in the 'Model' column. ${ }^{10}$ The reported $P$-tests have a $t$-distribution with just over 2,000 degrees of freedom. From column 1, the CES monopolistic competition model is mis-specified against the distance, income-similarity, and naive tariff models. Bearing in mind the large sample size and the likely low power of the $P$-test, one should be looking for very large values of the $P$-statistic. Surprisingly, there is only one very large P-statistic: 11.45 for the income-similarity model. The CES monopolistic competition model is resoundingly rejected by a model featuring trading-partner similarity in income and per capita income.

We have puzzled over why the CES model is only mis-specified against the incomesimilarity model. After all, each model would seem to be explaining different and important features of the data. The answer can be found by looking at correlations between $\ln M_{i j t}$ and its predictions. From column 3 of table 8, the correlations are by far the highest for the income-similarity model (0.67) and the CES monopolistic competition model (0.71). One can decompose such correlation into the correlation within country pairs and the correlation between country pairs. Within-country-pair correlations capture the evolution of trade flows over time. The between-country-pair correlations capture the differences in trade flows across country pairs. From column 4 , the income-similarity model has by far the highest within country-pair correlation. This is not hard to interpret. Trade flows are sensitive to business cycle conditions. The income-similarity model, with its GDP terms, is the model that best captures these Keynesian income dynamics. The flip side of this is that the CES monopolistic competition model does poorly at explaining cyclical trade movements.

Returning to issues of model mis-specification, we can also reverse the question asked. To what extent are the other models commonly considered in the literature mis-specified?

10 There is an issue in comparing the model $\ln M_{i j t}=\ln s_{i t} \Phi_{i j t} Q_{j t}+\lambda_{i j}+\varepsilon_{i j t}$ against an alternative $\ln M_{i j t}=$ $\beta X_{i j t}+\lambda_{i j}^{\prime}+\varepsilon_{i j t}^{\prime}$ in that rejection of no mis-specification may be coming from the difference between $\lambda_{i j}$ and $\lambda_{i j}^{\prime}$. This would be an uninteresting result. We therefore consider models with $\lambda_{i j}=\lambda_{i j}^{\prime}=0$. This means that we must add an intercept to the models. Further, since the alternative hypotheses all have many free parameters in the sense that they are identified only up to a linear transformation, we also add an additional slope parameter to the CES monopolistic competition model. Thus, the null hypothesis is $\ln M_{i j t}=\alpha+\beta \ln s_{i t} \Phi_{i j t}(\widehat{\sigma}) Q_{j t}+\varepsilon_{i j t}$ where $\varepsilon_{i j t}=\rho \varepsilon_{i j, t-1}+v_{i j t}$ and where the $v_{i j t}$ are independently and identically distributed. The ML estimate of $\sigma$ for this model (with an $\operatorname{AR}(1)$ correction, but no fixed effect, GLS, or first-observation corrections) is $\widehat{\sigma}=5.57$. The alternative hypothesis is $\ln M_{i j t}=\beta X_{i j t}+\varepsilon_{i j t}^{\prime}$ where $X_{i j t}$ is listed in the 'Model' column of table 8 and the $\varepsilon_{i j t}^{\prime}$ have the same properties as the $\varepsilon_{i j t}$. 
Given the large number of problems that we have identified with the CES model, the surprising feature is that many of the alternative models are also mis-specified. See column 2 of table 8 . These include the distance model $(P=11.06)$, the Heckscher-Ohlin model $(P=11.53)$, the Evenett-Keller-style model $(P=11.18)$, and the naive tariff model $(P=9.42)$. Thus, other models in the literature appear to suffer problems that are at least as severe as those faced by the CES monopolistic competition model.

\section{Conclusions}

As currently implemented, the workhorse econometric models of international trade (monopolistic competition, Heckscher-Ohlin, and gravity) do not rigorously incorporate product prices into their estimating equations and so are of limited value for assessing the welfare gains from trade liberalization. We modelled general equilibrium product price effects using the CES monopolistic competition model. We then estimated the model and, mimicking CGE models, used the model to estimate the compensating variation associated with trade liberalization. We estimated large welfare gains from liberalization. Unlike CGE models, we offered standard errors as well. These standard errors were surprisingly small and we offered a graphic explanation of this (figure 2).

However, standard errors are a very incomplete measure of whether or not a model is well-specified. Going beyond CGE models, we presented extensive specification testing aimed at isolating the violence done by the model to the data. We found a number of significant forms of mis-specification.

1. $\left(\ln \Phi_{i j t}\right)$ The price term - which captures the core behavioural and general equilibrium aspects of the model - is badly mis-specified. It explains only 16 percent of the variation in $\ln M_{i j t}$ (figure 3). Worse, it explains only 2 percent of the cleaner within country-pair sample variation i.e., the variation in $\ln M_{i j 1992}-\ln M_{i j 1972}$ (figure 4). This is a deeply disturbing result. It means that the tension between the model and the data is greatest for the price effects that lie at the heart of trade liberalization. 
2. $\left(\ln s_{i t}\right)$ The other core behavioural prediction of the CES monopolistic competition model is its prediction about unit income elasticities. We found that the income term $\ln s_{i t}$ explains 0 percent of the long-run, within country-pair sample variation (figure 5). Another piece of this 'income puzzle' is that the CES monopolistic competition model is mis-specified against the income similarity model precisely because the income similarity model is better at tracking medium-run Keynesian income dynamics (table 8).

3. (ln $Q_{j t}$ ) Taken together, these first two points mean that the good fit of the CES monopolistic competition model is being driven by the output term. It explains 21 percent of the within country-pair sample variation (figure 5). What makes this an odd result is that $Q_{j t}$ enters the model via a data identity (equation 4 ) and so has no behavioural or general equilibrium interpretation per se. What makes the situation even more puzzling is that $\ln Q_{j t}$ matters most for country pairs where $j$ (the exporter) is a poor country. One would have expected the model to work best when both partners are rich.

A number of more familiar empirical regularities also appeared. For one, there is substantial missing trade (figures 1 and 6). Part of this can be explained by our limited measure of trade restrictions, namely tariffs and discriminatory internal taxes, which exclude, for example, transport costs. However, it is equally clear that even after controlling for distance there remain spectacular differences between observed and predicted trade (figure 6). For another, trading partner similarity as measured by per capita GDP is an important determinant of trade (table 8), suggesting that product quality or other unobserved product attributes matter. Finally, we provided evidence that all of the major models of international trade are mis-specified (table 8).

It strikes us that the cart we have been riding is stuck up to its axels in mud - and empirical researchers will need help getting it unstuck. It also strikes us that the empirical anomalies listed above offer important theoretical guidance for the way ahead. First, our work on AR(1) modelling with fixed effects indicates that much more attention must be 
given to understanding trade dynamics. (See section 5.) Second, the dual role played by $\sigma$ as both a preference parameter and a mark-up parameter must be divorced. Separate preference and mark-up parameters are needed. (See sections 5 and 6.) Third, given that the good fit of the CES monopolistic competition model is driven by the output term $Q_{j t}$, more work is needed to understand how the location of production depends on tariffs in this class of models. Each of these three points is manageable. It is simply a question of persuading theorists and empirical researchers to start pulling on the same cart. 


\section{Appendix}

\section{Appendix A. The Maximum Likelihood Estimator}

We derive the likelihood function for a single industry and therefore drop the $g$ subscripts. We also set the $\delta_{i j}=1$ in order to minimize notation. Reintroducing the $\delta_{i j}$ is trivial. Define $\varepsilon_{i j} \equiv\left(\varepsilon_{i j 1}, \ldots, \varepsilon_{i j 5}\right)^{\prime}$. Then

$$
\mathbf{E} \varepsilon_{i j} \varepsilon_{i j}^{\prime}=\Omega_{i j} \equiv \frac{\left(\bar{s}_{i} \bar{s}_{j}\right)^{2 \omega} \eta^{2}}{1-\rho^{2}}\left[\begin{array}{cccc}
1 & \rho & \cdots & \rho^{4} \\
\rho & 1 & \cdots & \rho^{3} \\
\vdots & \vdots & \ddots & \vdots \\
\rho^{4} & \rho^{3} & \cdots & 1
\end{array}\right]
$$

Further, $\Omega_{i j}^{-1} \equiv\left[\left(\bar{s}_{i} \bar{s}_{j}\right)^{\omega} \eta\right]^{-2} \Psi$ where $\Psi$ is a $5 \times 5$ matrix with a diagonal band of $(1,1+$ $\left.\rho^{2}, 1+\rho^{2}, 1+\rho^{2}, 1\right)$, with bands just above and below the diagonal containing $-\rho$, and with zeroes elsewhere. It is straightforward to show that

$$
\varepsilon_{i j}^{\prime} \Omega_{i j}^{-1} \varepsilon_{i j}=\frac{1}{\left(\bar{s}_{i} \bar{s}_{j}\right)^{2 \omega} \eta^{2}}\left[\left(1-\rho^{2}\right) \varepsilon_{i j 1}^{2}+\sum_{t=2}^{5} v_{i j t}^{2}\right] .
$$

where $v_{i j t}=\varepsilon_{i j t}-\rho \varepsilon_{i j, t-1}$. Note that this is one of several ways of stating that we are working with the residual vector

$$
\varepsilon_{i j}^{\prime} \Omega_{i j}^{1 / 2}=\left(\sqrt{1-\rho^{2}} \varepsilon_{i j 1}, v_{i j 2}, \ldots, v_{i j 5}\right) /\left[\left(\bar{s}_{i} \bar{s}_{j}\right)^{2 \omega} \eta^{2}\right] .
$$

To develop the objective function recall that $\varepsilon_{i j t}=\ln M_{i j t}-\ln s_{i t} \Phi_{i j t}(\sigma) Q_{j t}-\lambda_{i j}$ and define $y_{i j t} \equiv \ln M_{i j t}, x_{i j t}(\sigma) \equiv \ln s_{i t} \Phi_{i j t}(\sigma) Q_{j t}, \Delta_{\rho} y_{i j t} \equiv y_{i j t}-\rho y_{i j, t-1}$, and $\Delta_{\rho} x_{i j t}(\sigma) \equiv$ $x_{i j t}(\sigma)-\rho x_{i j, t-1}(\sigma)$. Then the sum of squared errors is

$$
\begin{aligned}
& \operatorname{SSE}\left(\sigma, \rho, \omega, \eta,\left\{\lambda_{i j}\right\}_{\forall i j}\right)=\sum_{i=1}^{14} \sum_{j=1}^{36}\left(\bar{s}_{i} \bar{s}_{j}\right)^{-2 \omega} \eta^{-2} \\
& \times\left[\left(1-\rho^{2}\right)\left[y_{i j 1}-x_{i j 1}(\sigma)-\lambda_{i j}\right]^{2}+\sum_{t=2}^{5}\left[\Delta_{\rho} y_{i j t}-\Delta_{\rho} x_{i j t}(\sigma)-(1-\rho) \lambda_{i j}\right]^{2}\right] .
\end{aligned}
$$

The NLS estimator minimizes SSE. The ML estimator minimizes the loglikelihood function:

$$
\begin{aligned}
£\left(\sigma, \rho, \omega, \eta,\left\{\lambda_{i j}\right\}_{\forall i j}\right)= & -(5 \times 504 / 2) \ln \eta^{2}-5 \omega \Sigma_{i=1}^{14} \Sigma_{j=1}^{36} \ln \left(\bar{s}_{i} \bar{s}_{j}\right)+(504 / 2) \ln \left(1-\rho^{2}\right) \\
& -S S E\left(\sigma, \rho, \omega, \eta,\left\{\lambda_{i j}\right\}_{\forall i j}\right) / 2 .
\end{aligned}
$$


As a computational matter we work with the concentrated SSE and the concentrated $£$ e.g.,

$$
£^{\mathcal{C}}(\sigma, \rho, \omega, \eta)=\max _{\left\{\lambda_{i j}\right\}_{\forall i j}} £\left(\sigma, \rho, \omega, \eta,\left\{\lambda_{i j}\right\}_{\forall i j}\right) .
$$

The maximizing value of the fixed effects is given by ${ }^{11}$

$$
\lambda_{i j}^{\mathrm{ML}}=\frac{(1+\rho)\left(y_{i j 1}-x_{i j 1}(\sigma)\right)+\Sigma_{t=2}^{5}\left[\Delta_{\rho} y_{i j t}-\Delta_{\rho} x_{i j t}(\sigma)\right]}{(1+\rho)+(1-\rho)(5-1)} .
$$

To obtain the ML estimator with the first observation eliminated (column 6 of table 2), delete the equation (A 4$)$ term $\left(1-\rho^{2}\right)\left[y_{i j 1}-x_{i j 1}(\sigma)-\lambda_{i j}\right]^{2}$, replace the year total of 5 with 4 , and trivially recompute $\lambda_{i j}^{\mathrm{ML}}$.

\section{Appendix B. GMM IV}

This section describes the IV estimator of equation (13). Re-write this equation using the first difference operator $\Delta$ to obtain

$$
\Delta y_{i j t}=\rho \Delta y_{i j, t-1}+\Delta \Delta_{\rho} x_{i j t}(\sigma)+\Delta v_{i j t} \quad t>2 .
$$

The concern about endogeneity is that $\Delta y_{i j, t-1}$ and $\Delta \Delta_{\rho} x_{i j t}(\sigma)$ are correlated with $\Delta v_{i j t}$. Consider the moment restrictions in equation (14), namely, $\mathbf{E} y_{i j s} \Delta v_{i j t}=0$ for $s=$ $1, \ldots, t-2$ and $t>2$. Following a suggestion about differencing in Arellano (1989), we base our instruments on the following linear transformation of the moment restrictions: $\mathbf{E} y_{i j 1} \Delta v_{i j 3}=0, \mathbf{E} y_{i j 1} \Delta v_{i j 4}=0, \mathbf{E} \Delta y_{i j 2} \Delta v_{i j 4}=0, \mathbf{E} y_{i j 1} \Delta v_{i j 5}=0, \mathbf{E} \Delta y_{i j 2} \Delta v_{i j 5}=0$, and $\mathbf{E} \Delta y_{i j 3} \Delta v_{i j 5}=0$. These translate into the following instrument matrix for the three observations $(t=1982,1987$, and 1992) corresponding to country pair $(i, j)$ :

$$
Z_{i j}^{y} \equiv\left[\begin{array}{cccccc}
y_{i j 1} & 0 & 0 & 0 & 0 & 0 \\
0 & y_{i j 1} & \Delta y_{i j 2} & 0 & 0 & 0 \\
0 & 0 & 0 & y_{i j 1} & \Delta y_{i j 2} & \Delta y_{i j 3}
\end{array}\right] .
$$

From equation (15), another set of moment restrictions is $\mathrm{E} \Delta_{\rho} x_{i j s} \Delta v_{i j t}=0$ for $s=$ $1, \ldots, t-2$ and $t>2$. Applying a similar linear transformation as before while recognizing that the lack of availability of $x_{i j 0}$ makes $\Delta_{\rho} x_{i j 1}$ and $\Delta \Delta_{\rho} x_{i j 2}$ unavailable leads to the following linear transformation of the moment restrictions: $\mathbf{E} x_{i j 1} \Delta v_{i j 3}=0, \mathbf{E} x_{i j 1} \Delta v_{i j 4}=0$, $\mathrm{E} \Delta_{\rho} x_{i j 2} \Delta v_{i j 4}=0, \mathbf{E} x_{i j 1} \Delta v_{i j 5}=0, \mathbf{E} \Delta_{\rho} x_{i j 2} \Delta v_{i j 5}=0$, and $\mathbf{E} \Delta \Delta_{\rho} x_{i j 3} \Delta v_{i j 5}=0$. The use of

\footnotetext{
${ }^{11}$ It is of interest to note that the effective degrees of freedom per $(i, j)$ pair is given by the denominator of this expression so that if $\rho$ is close to 1 the effective degrees of freedom is 2 . That is, the greater is the serial correlation, the smaller is the effective degrees of freedom.
} 
differences $\Delta \Delta_{\rho} x_{i j 3}$ rather than levels $\Delta_{\rho} x_{i j 3}$ is endorsed by (Sevestre and Trognon, 1996, page 129). These transformed moment restrictions translate into the instrument matrix

$$
Z_{i j}^{x} \equiv\left[\begin{array}{cccccc}
x_{i j 1} & 0 & 0 & 0 & 0 & 0 \\
0 & x_{i j 1} & \Delta_{\rho} x_{i j 2} & 0 & 0 & 0 \\
0 & 0 & 0 & x_{i j 1} & \Delta_{\rho} x_{i j 2} & \Delta \Delta_{\rho} x_{i j 3}
\end{array}\right] .
$$

Finally, when the $x_{i j t}$ are exogenous we have the additional moment restrictions $\mathrm{E} \Delta_{\rho} x_{i j s} \Delta v_{i j t}=0$ for $s=t-1, t$ and $t>2$. This leads to the moment restrictions $\mathrm{E} \Delta \Delta_{\rho} x_{i j 3} \Delta v_{i j 3}=0, \mathrm{E} \Delta \Delta_{\rho} x_{i j 3} \Delta v_{i j 4}=0, \mathrm{E} \Delta \Delta_{\rho} x_{i j 4} \Delta v_{i j 4}=0, \mathrm{E} \Delta \Delta_{\rho} x_{i j 3} \Delta v_{i j 5}=0$, $\mathrm{E} \Delta \Delta_{\rho} x_{i j 4} \Delta v_{i j 5}=0$, and $\mathrm{E} \Delta \Delta_{\rho} x_{i j 5} \Delta v_{i j 5}=0$ which in turn translate into the instrument matrix

$$
Z_{i j}^{x \prime} \equiv\left[\begin{array}{cccccc}
\Delta \Delta_{\rho} x_{i j 3} & 0 & 0 & 0 & 0 & 0 \\
0 & \Delta \Delta_{\rho} x_{i j 3} & \Delta \Delta_{\rho} x_{i j 4} & 0 & 0 & 0 \\
0 & 0 & 0 & \Delta \Delta_{\rho} x_{i j 3} & \Delta \Delta_{\rho} x_{i j 4} & \Delta \Delta_{\rho} x_{i j 5}
\end{array}\right] .
$$

We can now define the GMM objective function. When the $x_{i j t}$ are exogenous define $Z_{i j}$ as $Z_{i j}=\left[\begin{array}{ll}Z_{i j}^{y} & Z_{i j}^{x \prime}\end{array}\right]$. When the $x_{i j t}$ are endogenous define $Z_{i j}$ as $Z_{i j}=\left[\begin{array}{ll}Z_{i j}^{y} & Z_{i j}^{x}\end{array}\right]$. Let $Z$ be the stacked $Z_{i j}$. $Z$ has 1,512 rows (36 exporters $\times 14$ importers $\times 3$ years) and 12 columns. Let $\Delta v$ be the stacked residuals. The GMM estimator minimizes $\Delta v^{\prime} P_{Z} \Delta v$ where $P_{Z} \equiv Z A_{N} Z^{\prime}, A_{N} \equiv 36 \times 14\left(\Sigma_{i j} Z_{i j}^{\prime} \Omega Z_{i j}\right)^{-1}$ and $\Omega$ is a $(3 \times 3$ matrix with twos on the diagonal, minus ones on the first subdiagonals and zeroes otherwise. $\Omega$ is the GLS correction for the fact that $\mathbf{E}\left(v_{i j t}-v_{i j, t-1}\right)^{2}=2 \mathbf{E} v_{i j t}^{2}=2 \eta^{2}$ and $\mathbf{E}\left(v_{i j t}-v_{i j, t-1}\right)\left(v_{i j, t-1}-\right.$ $\left.v_{i j, t-2}\right)=-\mathbf{E} v_{i j, t-1}^{2}=-\eta^{2}$ where $\eta^{2}$ is defined in equation (9) (with $\omega=0$ ).

\section{Appendix C. The Tariff Data}

Bilateral tariff rates for our 14 importers (see table 1) are from the following sources:

A. UNCTAD's 1993 TRAINS database (CD-ROM). This contains complete bilateral tariff data $\tau_{g i j t}^{A}$ for all 36 countries in 1992. Data on preferential agreements and discriminatory internal taxes are described in the extensive table notes included with the CD-ROM. The classification system is the Harmonized System (HS).

B. The Tokyo-Round GATT Tariff Study. This contains complete bilateral tariff data $\tau_{\text {gijt }}^{B}$ for our 14 importers for the years 1979, 1983, and 1987. The data were originally developed for Trefler (1993). The classification system is HS.

C. The Kennedy-Round GATT Tariff Study as reported in Deardorff and Stern (1986). This contains average tariff data $\tau_{\text {git }}^{C}$ for all of our importers (except Greece) for 1972 and 1979. It also includes Sweden, Austria, Australia, and New Zealand. The classification system is ISIC(Rev. 2). 
D. Government Finance Statistics Yearbook (GFS) and International Finance Statistics Yearbook

(IFS). These publications contain data on import duties, total imports and hence tariff rates $\tau_{i t}^{D}$ for all 36 countries for the $1972-92$ period. There is no industry dimension.

Data sources A and B were converted to 3-digit ISIC using a converter we developed from Statistics Canada data. The resulting data for 1979, 1983, 1987, and 1992 were then combined with data source $\mathrm{C}$ to obtain 1972 data using the formula

$$
\tau_{g i j 72}=\tau_{\text {gij79 }}^{B}\left(\tau_{\text {gi72 }}^{C} / \tau_{\text {gi79 }}^{C}\right) .
$$

(For Greece, the formula is the same, but with $\tau_{\text {git }}^{C}$ replaced by $\tau_{i t}^{D}$.) Since tariff concessions were linear (the so-called 'Swiss Rule') and MFN-based over the 1972-79 period, this formula will be quite accurate. Data for 1977 and 1982 are close enough to 1979 and 1983 to be linearly interpolated accurately. The result is complete data for 1972, 1977, 1982, 1987, and 1992.

As discussed in section 2, the only place where the $\tau_{\text {gijt }}$ for the remaining 22 countries enter the estimating equation is in the denominator of equation (6). The $\tau_{g i j t}$ thus play a very limited role. Therefore, it is much less important to have accurate bilateral tariff rates for these remaining 22 countries. The data sources for these countries are, in addition to the above,

E. OECD Indicators of Tariff and Non-tariff Trade Barriers (CD-ROM). This contains average tariff data $\tau_{\text {git }}^{E}$ for Sweden, Austria, Spain, Portugal, Australia, and New Zealand in 1988 and 1992. The classification system is ISIC.

F. UNCTAD Directory of Import Regimes (DIR). This UNCTAD publication contains average tariff rates $\tau_{\text {git }}^{F}$ for the remaining 16 non-OECD countries. The data are for 3 years, one each from the 1981-83, 1984-1986, and 1987-89 periods. The classification system is closely related to ISIC.

The data for the remaining 22 countries were constructed as follows. For Sweden, Austria, Australia, and New Zealand we used the formula in equation (A 10), but with data source $\mathrm{E}$ in place of $\mathrm{C}$ for 1988 and data source $\mathrm{C}$ augmented by $\mathrm{D}$ for earlier years e.g., $\tau_{g i j 88}=$ $\tau_{\text {gij92 }}^{A}\left(\tau_{\text {gi88 }}^{E} / \tau_{\text {gi }}^{E}\right)$. For Spain and Portugal we used the formula in equation (A 10), but with data source $E$ in place of $C$ for 1988 and data source $D$ for earlier years. For the 16 remaining (developing) countries we again used the formula in equation (A 10), but with data source $F$ in place of $C$ for the 1980s and data source $D$ for earlier years.

\section{Appendix D. Identification}

Identification of the $\sigma_{g}$ is not a trivial matter. Consider the simple case where there is no home bias $\left(\delta_{g i j}=1\right.$ for all $i$ and $\left.j\right)$ and where tariffs are applied on an MFN basis $\left(\tau_{g i j}=\tau_{g i}\right.$ 
Table 9. Bilateral Tariff Rates for Aggregate Manufacturing, 1992

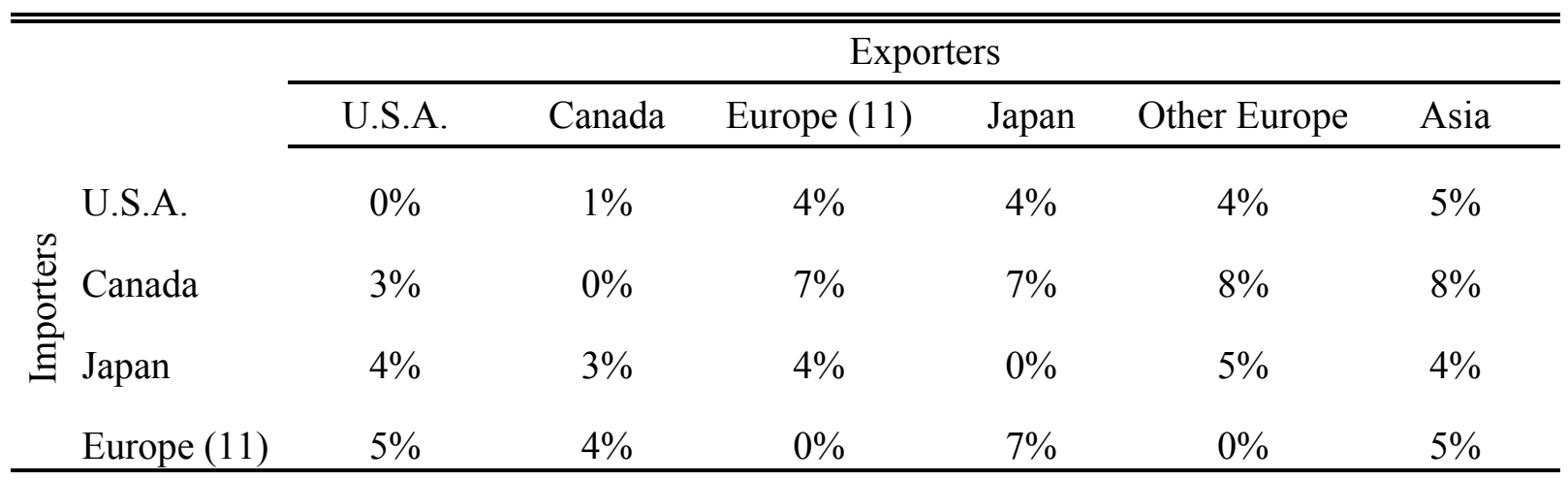

Notes: Tariff rates include discriminatory internal taxes.

for all $g, i$ and $j)$. In this case, $\sigma_{g}$ disappears as an argument of $\Phi_{g i j}\left(\sigma_{g}\right)$. That is, $\sigma_{g}$ is not identified. This is re-assuring for it means that we are identifying $\sigma_{g}$ off the right source of sample variation, namely, each importer's tariff variation across time and partners (as opposed to variation across importers).

In light of this, departures from MFN are a key source of sample variation. This raises the question of whether a country's tariff variation across partners is due to departures from MFN or to aggregation bias associated with product mix differences within 3-digit ISIC industries. Table 9 sheds light on this. For the United States, average 1992 tariff rates are similar across all trading partners except Canada. This reflects the Canada-U.S. Free Trade Agreement. Hence, the tariff variation is due to departures from MFN. Likewise for Canada. For Europe, most of the sample variation is associated with the European customs union. However, there is some variation across non-European partners which evidences aggregation bias. This bias disappears when we move to the 3-digit ISIC level. The conclusion, then, is that it is preferential trading arrangements rather than aggregation bias that drives the sample variation. This is reassuring.

\section{Appendix E. Estimates of $\sigma_{g}$ By Industry}

Table 10 reports the ML results by industry for the baseline specification in column 1 of table 2. Except for 3 industries (Petroleum products, petroleum refining, and instruments), the $\widehat{\sigma}_{g}$ are all positive. However, no obvious pattern jumps out in which the rank of the $\widehat{\sigma}_{g}$ is readily related to a priori industry characteristics. For example, the industries with the largest $\widehat{\sigma}_{g}$ are industrial chemicals and electric and electronic equipment.

Implicitly we are judging the reasonableness of the $\widehat{\sigma}_{g}$ by asking whether they are small for industries that are best characterized by monopolistic competition and large 
Table 10. Estimates by Industry

\begin{tabular}{|c|c|c|c|}
\hline & \multicolumn{2}{|c|}{ ML Estimator } & \multirow{3}{*}{$\begin{array}{c}\text { Correlation of } \\
\ln \left(M_{g i j t}\right) \text { with } \\
\ln \left(s_{i t} \Phi_{g i j t} Q_{g j t}\right) \\
(3)\end{array}$} \\
\hline & $\sigma_{g}$ & Std. Err. & \\
\hline & (1) & (2) & \\
\hline Food Products & 2.53 & 0.67 & 0.84 \\
\hline Industrial Chemicals & 21.41 & 0.98 & 0.81 \\
\hline Elec. Mach. \& Electronics & 18.86 & 0.79 & 0.81 \\
\hline Machinery, Non-electric & 12.13 & 0.84 & 0.80 \\
\hline Misc. Manufacturing & 14.42 & 0.92 & 0.80 \\
\hline Pharmaceuticals etc & 15.99 & 0.98 & 0.77 \\
\hline Plastic Products & 15.69 & 0.56 & 0.77 \\
\hline Textiles & 3.50 & 0.72 & 0.75 \\
\hline Fabricated Metal Products & 7.48 & 0.65 & 0.74 \\
\hline Instruments & -5.43 & 1.54 & 0.73 \\
\hline Leather Products & 6.02 & 1.93 & 0.69 \\
\hline Non-ferrous Metals & 8.13 & 1.06 & 0.66 \\
\hline Transport Equipment & 3.10 & 1.30 & 0.65 \\
\hline Clay \& Cement Products & 7.71 & 0.98 & 0.64 \\
\hline Apparel & 4.25 & 0.53 & 0.63 \\
\hline Glass Products & 5.41 & 0.74 & 0.61 \\
\hline Wood Products & 2.91 & 0.69 & 0.60 \\
\hline Iron \& Steel & 13.74 & 2.15 & 0.59 \\
\hline Rubber Products & 15.81 & 1.48 & 0.59 \\
\hline Beverages & 3.71 & 0.64 & 0.58 \\
\hline Printing \& Publishing & 1.15 & 0.79 & 0.57 \\
\hline Furniture & 8.74 & 0.89 & 0.53 \\
\hline Pottery \& China & 5.41 & 0.98 & 0.49 \\
\hline Pulp \& Paper & 4.79 & 1.57 & 0.49 \\
\hline Footwear & 5.59 & 0.74 & 0.41 \\
\hline Tobacco & 1.96 & 0.22 & 0.29 \\
\hline Petroleum Refineries & -0.16 & 2.09 & 0.18 \\
\hline Misc. Petro \& Coal Prods. & -9.72 & 2.19 & 0.13 \\
\hline
\end{tabular}

Notes: Each specification is in logs with AR(1), fixed effect, and GLS corrections. There is no home bias $\left(\delta_{i j}=1\right.$ for all $i$ and $\left.j\right)$ in any specification. 
for industries that are best characterized by perfect competition. By this criterion, the $\widehat{\sigma}_{g}$ are not reasonable. A very different criterion recognizes that one size does not fit all. For industries that are poorly characterized by monopolistic competition the estimates of the $\widehat{\sigma}_{g}$ should be meaningless. If so, we should examine whether the correlation between predicted and actual imports is highest for industries best characterized by monopolistic competition. Table 10 does just this. It sorts industries by the correlation between $\ln M_{g i j t}$ and $\ln s_{i t} \Phi_{g i j t} Q_{j t}$. This criterion makes some sense of the estimates. The correlation between columns 1 and 3 is 0.59 . By and large, the top of the list is dominated by industries best characterized by monopolistic competition e.g., electric and electronic equipment, pharmaceuticals, and machinery. Likewise, the bottom of the list is dominated by industries that are more perfectly competitive such as pulp and paper, footwear, and furniture. There are, of course, exceptions such as transport equipment. By and large though, table 10 supports the view that the model works well for industries that are best characterized by monopolistic competition and the model works very poorly elsewhere. 


\section{References}

Anderson, James E. and Douglas Mercouiller, "Trade, Insecurity, and Home Bias: An Empirical Investigation," Working Paper 7000, National Bureau of Economic Research 1999.

Antweiler, Werner, “Trade vs. the Environment: New Empirical Evidence," 1995. Mimeo, University of British Columbia.

- and Daniel Trefler, "Increasing Returns and All That: A View From Trade," American Economic Review, March 2002, 92, 93-119.

Arellano, Manuel, "A Note on the Anderson-Hsiao Estimator for Panel Data," Economics Letters, December 1989, 31 (4), 337-341.

- and Stephen Bond, "Some Tests of Specification for Panel Data: Monte Carlo Evidence and an Application to Employment Equations," Review of Economic Studies, April 1991, $58,277-297$.

Armington, Paul S., "A Theory of Demand for Products Distinguished by Place of Production," International Monetary Fund Staff Papers, March 1969, 16, 159-176.

Barro, Robert and Jong-Wha Lee, "International Comparisons of Educational Attainment," Journal of Monetary Economics, 1993, 32 (3), 363-394.

Berry, Steven, James Levinsohn, and Ariel Pakes, "Voluntary Export Restraints on Automobiles: Evaluating a Trade Policy," American Economic Review, June 1999, 89, 400-430.

Brown, Drusilla K. and Robert M. Stern, "Computable General Equilibrium Estimates of the Gains from U.S.-Canadian Trade Liberalization," in David Greenaway, Thomas Hyclak, , and Robert J. Thornton, eds., Economic Aspects of Regional Trading Arrangements, New York: New York University Press, 1989.

Davidson, Russell and James G. MacKinnon, Estimation and Inference in Econometrics, New York: Oxford University Press, 1993.

Dawkins, Christina, T.N. Srinivasan, and John Whalley, "Calibration," in James J. Heckman and Edward Leamer, eds., Handbook of Econometrics, Vol. 5, Amsterdam: NorthHolland, 2001.

Deardorff, Alan V. and Robert M. Stern, The Michigan Model of World Production and Trade: Theory and Applications, Cambridge: MIT Press, 1986.

_, - , and Christopher F. Baum, "A Multi-Country Simulation of the Employment and Exchange-Rate Effects of Post-Kennedy Round Tariff Reductions," in N. Akrasanee et al., ed., Trade and Employment in Asia and the Pacific, Honolulu: The University Press of Hawaii, 1977, pp. 36-66.

Debaere, Peter, "Testing "New" Trade Theory without Testing for Gravity: ReInterpreting the Evidence," 2002. NBER Working Paper \#4580. 
Dixit, Avinash K. and Joseph E. Stiglitz, "Monopolistic Competition and Optimum Product Diversity," American Economic Review, June 1977, 67 (3), 297-308.

Eaton, Jonathan and Samuel Kortum, "Technology, Geography, and Trade," Econometrica, forthcoming, 2002.

Evenett, Simon J. and Wolfgang Keller, "On Theories Explaining the Success of the Gravity Equation," Journal of Political Economy, April 2002, 110, 281-316.

Feenstra, Robert C., "Gains from Trade in Differentiated Products: Japanese Compact Trucks," in Robert C. Feenstra, ed., Empirical Models for International Trade, Cambridge MA: MIT Press, 1988.

_ , "New Product Varieties and the Measurement of International Prices," American Economic Review, March 1994, 84 (1), 157-177.

_ , "Estimating the Effects of Trade Policy," in Gene M. Grossman and Kenneth Rogoff, eds., Handbook of International Economics, Vol. 3, Amsterdam: Elsevier, 1995.

- and James Levinsohn, "Estimating Markups and Market Conduct with Multidimensional Product Attributes," Review of Economic Studies, January 1995, 62 (1), $19-52$.

Hallak, Juan Carlos, "The Effects of Cross-Country Differences in Product Quality on International Trade Flows," 2001. Mimeo, Harvard University.

Hanson, Gordon H., "Market Potential, Increasing Returns, and Geographic Concentration," Working Paper 1998, National Bureau of Economic Research 1998.

Harrigan, James, "OECD Imports and Trade Barriers in 1983," Journal of International Economics, August 1993, 35 (1-2), 91-111.

_ , "Openness to Trade in Manufactures in the OECD," Journal of International Economics, February 1996, 40 (1-2), 23-39.

Harris, Richard, "Applied General Equilibrium Analysis of Small Open Economies with Scale Economies and Imperfect Competition," American Economic Review, December 1984, 74, 1016-1032.

Harrison, Ann E., "Productivity, Imperfect Competition and Trade Reform: Theory and Evidence," Journal of International Economics, February 1994, 36 (1-2), 53-73.

Harrison, Glenn W., Thomas F. Rutherford, and David G. Tarr, "Quantifying the Uruguay Round," Economic Journal, September 1997, 107, 1405-1430.

Hausman, Jerry A., "Specification Tests in Econometrics," Econometrica, November 1978, $46(6), 1251-1271$.

Haveman, Jon D., Usha Nair Reichert, and Jerry Thursby, "Trade Reduction, Diversion and Compression: Empirical Regularities in the Effects of Protective Measures," 1999. Mimeo, Purdue University. 
Helpman, Elhanan, "Imperfect Competition and International Trade: Evidence from Fourteen Industrial Countries," Journal of the Japanese and International Economies, March 1987, 1 (1), $62-81$.

- and Paul R. Krugman, Market Structure and Foreign Trade: Increasing Returns, Imperfect Competition, and the International Economy, Cambridge, MA: MIT Press, 1985.

Hummels, David and James Levinsohn, "Product Differentiation as a Source of Comparative Advantage?," American Economic Review Papers and Proceedings, May 1993, 83 (2), $445-449$.

_ and _ , "International Trade and Monopolistic Competition: Reconsidering the Evidence," Quarterly Journal of Economics, August 1995, 110 (3), 799-836.

Jensen, Paul E., "Analysis of Bilateral Trade Patterns With Panel Data," Review of International Economics, 2000, 8 (1), 86-99.

Lai, Huiwen, "Essays in International Trade and Financial Economics," Ph.D. Dissertation, University of Toronto 1999.

Lawrence, Robert Z., "Imports in Japan: Closed Markets or Minds?," Brookings Papers on Economic Activity, 1987, 2, 517-548.

Leamer, Edward E., Robert M. Stern, and Christopher F. Baum, "An Empirical Analysis of the Composition of Manufacturing Employment in the Industrialized Countries," European Economic Review, April 1977, 9 (1), 1-19.

Levinsohn, James, "Testing the Imports-as-Market-Discipline Hypothesis," Journal of International Economics, August 1993, 35 (1-2), 1-22.

Nickell, Stephen J., "Biases in Dynamic Models with Fixed Effects," Econometrica, November 1981, 49 (6), 1417-26.

Saxonhouse, Gary R., "Differentiated Products, Economies of Scale, and Access to the Japanese Market," in Robert C. Feenstra, ed., Trade Policies for International Competitiveness, Chicago: University of Chicago Press, 1989.

Schott, Peter K., "Do Rich and Poor Countries Specialize in a Different Mix of Goods? Evidence from Product-Level US Trade Data," Working Paper 8492, National Bureau of Economic Research September 2001.

Sevestre, Patrick and Alain Trognon, "Dynamic Linear Models," in László Mátyás and Patrick Sevestre, eds., The Econometrics of Panel Data: A Handbook of the Theory with Applications, Second Revised Edition, Dordrecht: Kluwer Academic Publishers, 1996.

Shiells, Clinton R. and Kenneth A. Reinert, "Trade Substitution Elasticities for Analysis of a North American Free Trade Area," Working Paper 91-01-B (Revised), Office of Economics, U.S. International Trade Commission 1991.

Summers, Robert and Alan Heston, "The Penn World Table (Mark 5): An Expanded Set of International Comparisons, 1950-1988," Quarterly Journal of Economics, May 1991, 106 (2), 327-68. 
Trefler, Daniel, "Trade Liberalization and the Theory of Endogenous Protection: An Econometric Study of U.S. Import Policy," Journal of Political Economy, February 1993, $101(1), 138-160$.

- , "The Case of the Missing Trade and Other Mysteries," American Economic Review, December 1995, 85 (5), 1029-1046.

Wei, Sahang-Jin, "Intra-National Versus International Trade: How Stubborn are Nations in Global Integration?," Working Paper 5531, National Bureau of Economic Research April 1996. 